\title{
Electrocatalyst engineering and structure-activity relationship in hydrogen evolution reaction: From nanostructures to single atoms
}

\author{
Yuan Pan $^{1,2}$, Chao Zhang ${ }^{2}$, Yan Lin $^{3}$, Zhi Liu ${ }^{1}$, Minmin Wang ${ }^{1}$ and Chen Chen ${ }^{2 *}$
}

\begin{abstract}
With the ever-pressing issues of global energy demand and environmental pollution, molecular hydrogen has been receiving increasing attention as a clean alternative energy carrier. For hydrogen production, the design and development of high-performance catalysts remains rather challenging. As the compositions and structures of catalyst interfaces have paramount influences on the catalytic performances, the central topic here has always been to design and engineer the interface structures via rational routes so as to boost the activities and stabilities of electrocatalysts on hydrogen evolution reaction (HER). Here in this review, we focus on the design and preparation of multi-scale catalysts specifically catering to HER applications. We start from the design and structure-activity relationship of catalytic nanostructures, summarize the research progresses related to HER nanocatalysts, and interpret their high activities from the atomistic perspective; then, we review the studies regarding the design, preparation, HER applications and structure-activity relationship of single-atom site catalysts (SASCs), and thereupon discuss the future directions in designing HER-oriented SASCs. At the end of this review, we present an outlook on the development trends and faced challenges of catalysts for electrochemical HER.
\end{abstract}

Keywords: electrocatalyst, structure-activity relationship, hydrogen evolution reaction, nanomaterials, single-atom site catalysts

\section{INTRODUCTION}

With the ever-growing global energy demand and everpressing environment issues, the concept of "hydrogen economy" has received ever-broadening acknowledgement. Ironically, 95\% of the global hydrogen supply now comes (directly or indirectly) from fossil fuels, which, in essence, is in contradiction with the intention of green and sustainable development [1,2]. The water on the Earth constitutes a gigantic reservoir for hydrogen; however, the production of hydrogen from water by electrochemical method is a rather energy-intensive and expensive process, thus not competitive with hydrogen production from fossil fuels. In order to reduce the total energy consumption, the overpotentials in water splitting have to be lowered, and the efficiency has to be elevated [3]. Up to date, relevant catalysts with the highest efficiencies have been $\mathrm{Pt}$ and Pt-group metals, which generally suffer from low abundance and high costs, and are therefore unsuitable for large-scale applications in industry [4]. As a result, it has become an urgent task to develop catalysts based on low-cost non-noble metals or single-atom site catalysts (SASCs) featuring low loadings and high activities.

The compositions and structures of surfaces/interfaces of catalysts are known to have great influences on their catalytic performances; one of the central topics in hydrogen evolution reaction (HER) has always been to rationally design and manipulate the chemical compositions, atom arrangement and electronic structures at the catalyst interfaces to boost the activity and stability [5]. Therefore, the key science in catalyst design and preparation is to select the appropriate materials, and

\footnotetext{
${ }^{1}$ State Key Laboratory of Heavy Oil Processing, China University of Petroleum (East China), Qingdao 266580, China

${ }^{2}$ Department of Chemistry, Tsinghua University, Beijing 100084, China

${ }^{3}$ College of Science, China University of Petroleum (East China), Qingdao 266580, China

${ }^{*}$ Correspondence author (email: cchen@mail.tsinghua.edu.cn)
} 
thereupon to construct specific interface structures and to arrange the surface atoms in optimized configurations. For the preparation methodology of advanced catalysts, scientists need to develop new techniques, including (1) manipulating the nanocatalysts at the atomic level, and (2) fabricating catalytically active single-atom sites.

In this review (Fig. 1), we focus on the multi-scale design and preparation of catalysts for the HER system. We start from the design and structure-activity relationship of catalytic nanostructures, summarize the research progresses related to HER nanocatalysts, and interpret their high activities from the atomistic perspective; then, we review the studies regarding the design, preparation, HER applications and structure-activity relationship of SASCs, and thereupon discuss the future directions in designing HER-oriented SASCs. At the end of this review, we present an outlook on the development trends and faced challenges of electrocatalysts for HER.

\section{NANOCATALYST ENGINEERING FOR HER}

\section{Noble metal nanocatalysts}

Noble metal Pt is considered as the state-of-the-art HER electrocatalyst for its much lower overpotential at the same current density than those of other materials. However, the large-scale industrial applications of this metal are limited by its low abundance in the Earth's crust. In order to reduce the usages, maximize the atom efficiencies and maintain the high activities, microstructured, nanostructured even single-atom electrocatalysts with more exposed catalytic atoms have been in pursuit [6,7]. As reported by Chen et al. [8], the shape of Pt nanocrystals affects their catalytic activity and selectivity for many electrocatalytic reactions (such as oxygen reduction reaction (ORR), oxidation reaction of methanol, ethanol, and formic acid), but for HER the activity is mainly mentioned under the general test conditions. Li et al. [9] reported an under-water, super-

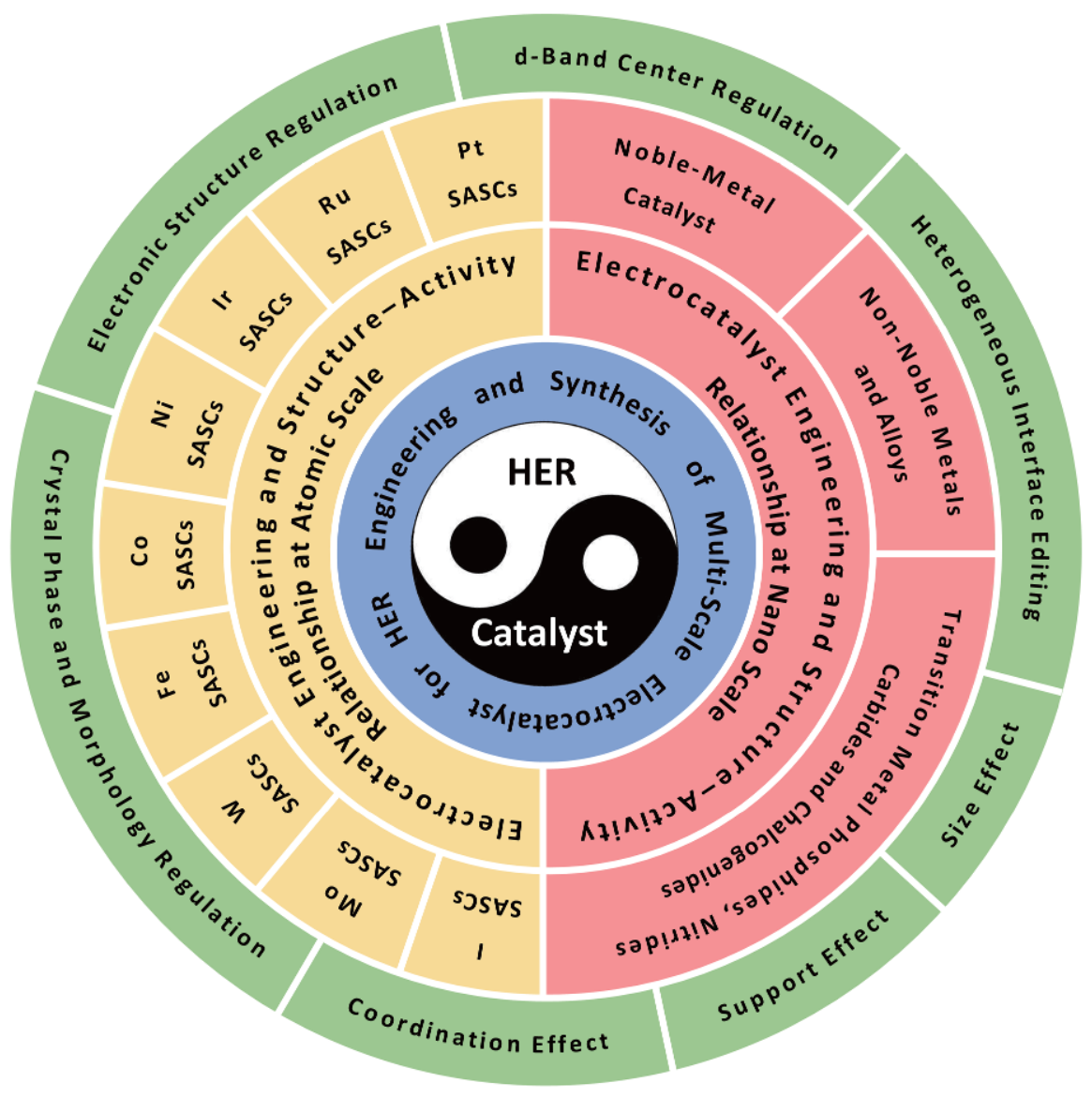

Figure 1 The summarized schematic illustration of the research routes in this review. 
aerophobic, nanostructured Pt electrode with a pine-like shape, which shows much better electrocatalytic HER performances, with a dramatically abrupt increase in current density with overpotential $\left(3.85 \mathrm{~mA} \mathrm{mV}^{-1}\right)$, which is 2.55 and 13.75 times higher than that of Pt nanospheres and $\mathrm{Pt}$ flat electrodes. Introducing carbon materials is an effective way to design various novel Ptbased nanocatalysts for HER. Bai et al. [10] prepared a unique Pd@Pt/graphene hybrid structure with Pt shell thickness tunable $(0.8-3.2 \mathrm{~nm})$ (Fig. 2a-c). The results suggest the Pt shell thickness greatly affects the HER performance. When the shell thickness is reduced to $0.8 \mathrm{~nm}$, the highest HER performance can be achieved $\left(791 \mathrm{~mA} \mathrm{~cm}^{-2}\right.$ at $300 \mathrm{mV}$, Tafel slope of $10 \mathrm{mV} \mathrm{dec}^{-1}$ ) (Fig. $2 \mathrm{~d}$ and e). The team proposed a surface polarization mechanism, by which the shell thickness can be minimized, thus reducing the usage of Pt.

Another effective way is reducing the Pt loadings while better utilizing its high activity by combining other earthabundant elements. Esposito et al. [11] selected "Pt-like" transition metal carbides (such as tungsten carbides, WCs) to support the lowest possible loading (monolayer) of Pt. Their studies suggest that replacing Pt atoms with WC would not compromise the electrocatalytic activity, and can also reduce the Pt loading in various electrocatalytic applications by over an order of magnitude. They also tried to support one Pt monolayer on molybdenum carbide $\left(\mathrm{Mo}_{2} \mathrm{C}\right)$ to reduce the cost. The results suggest that this catalyst shows a Pt-like activity and excellent stability under HER conditions. Xing et al. [12] used a three-dimensional (3D) substrate (carbon cloth supported $\mathrm{Co}(\mathrm{OH})_{2}$ nanosheet (NS) array $\left(\mathrm{Co}(\mathrm{OH})_{2} /\right.$ CC)) for Pt electrodeposition, and obtained a sample denoted as $\mathrm{Pt}-\mathrm{Co}(\mathrm{OH})_{2} / \mathrm{CC}$ (with $5.7 \mathrm{wt} \% \mathrm{Pt}$ loading). It showed top performances for HER in both alkaline and neutral conditions (4.8 and 2.6 times higher than those of commercial Pt/C/CC, respectively). The synergistic catalytic effects between $\mathrm{Co}(\mathrm{OH})_{2}$ and $\mathrm{Pt}$ at the nano-interfaces led to the greatly improved performances. Similarly, Xie et al. [13] directly grew an ultralow-Pt-content (5.1 wt\%) $\mathrm{Ni}(\mathrm{OH})_{2}-\mathrm{PtO}_{2}$ hybrid $\mathrm{NS}$ array on Ti mesh (the resulting product denoted as $\left.\mathrm{Ni}(\mathrm{OH})_{2}-\mathrm{PtO}_{2} \mathrm{NS} / \mathrm{Ti}\right)$. It exhibits a superior activity $\left(31.4 \mathrm{mV}\right.$ at $\left.4 \mathrm{~mA} \mathrm{~cm}^{-2}\right)$ in $0.1 \mathrm{~mol} \mathrm{~L}^{-1} \mathrm{KOH}$. This catalyst also shows an excellent stability, with nearly $100 \%$ faradaic efficiency after at least $100 \mathrm{~h}$. Density functional theory (DFT) calculations reveal that the interface formed between $\mathrm{Ni}(\mathrm{OH})_{2}$ and $\mathrm{PtO}_{2}$ greatly promotes the $\mathrm{H}_{2} \mathrm{O}$ dissociation kinetics and optimizes the hydrogen adsorption free energy, thus boosting the HER process. Tiwari et al. [14] used mela- mine-derived graphitic tubes (GTs) to anchor a multicomponent catalyst with ultralow Pt loading $(1.4 \mu \mathrm{g} /$ electrode area $\left(\mathrm{cm}^{2}\right)$ ). With a Pt loading only $1 / 80$ of that for commercial $20 \% \mathrm{Pt} / \mathrm{C}$, this catalyst only needs $18 \mathrm{mV}$ to deliver $10 \mathrm{~mA} \mathrm{~cm}^{-2}$ in $0.5 \mathrm{~mol} \mathrm{~L}^{-1} \mathrm{H}_{2} \mathrm{SO}_{4}$, and gives a turnover frequency (TOF) 96 times higher $\left(7.22 \mathrm{~s}^{-1}\right)$ than that for $\mathrm{Pt} / \mathrm{C}$ catalyst, and it also shows a long-term durability (for 10,000 cycles).

Downsizing Pt nanoparticles (NPs) to clusters or even single atoms can maximize the exposure of active sites and then greatly reduce the usage, which is desirable for Pt-related industrial applications [15]. Wang et al. [16] designed ultrafine Pt nanoclusters (NCs) confined by a trigonal prismatic coordination cage (Fig. 2f-h). The HER electrocatalytic activity of the Pt NCs is higher than that of commercial Pt/C (Fig. 2i and $j$ ) owing to the highly active surface, as well as the synergism between $\mathrm{Pt}$ NCs and cage matrix. Besides, downsizing Pt to singleatom scale can maximize the atom utilization by exposing nearly all the metal atoms as active sites, which will be discussed later (vide infra). Alloying Pt-group metals with other non-noble metals (such as $\mathrm{Cu}[17,18], \mathrm{Fe}$ [19], Co $[20,21])$ can also be used to lower the loading. Previous studies have suggested that metal Ni possesses a moderate hydrogen binding energy close to that of $\mathrm{Pt}$, and $\mathrm{Pt}-\mathrm{Ni}$ alloy may thus exhibit profitable electronic and synergistic effect for HER. Solvothermal method has been proved competent for the preparation of Pt-Ni alloys. Hexagonal close-packed Pt-Ni alloy nano-multipods were prepared through a facile one-pot solvothermal method by Cao et al. [5]. This Pt-Ni nano-multipods show superior HER catalytic performance in alkaline condition $\left(65 \mathrm{mV}\right.$ at $10 \mathrm{~mA} \mathrm{~cm}^{-2}$, mass current density is $3.03 \mathrm{~mA} \mathrm{mg}(\mathrm{Pt})^{-1}$ at $-70 \mathrm{mV}$ ) thanks to the unique crystal structure and excavated polyhedral morphology. Zhang et al. [21] also prepared Pt-Ni anisotropic superstructures (Pt-Ni ASs) through a solvothermal method, which showed spatial heterogeneity (Fig. $2 \mathrm{k}-\mathrm{m}$ ). Fourier transforms of EXAFS spectra of Pt L3-edge and Ni Kedge demonstrated the formation of Pt-Ni ASs (Fig. 2n and o). The HER electrocatalytic performances $(27.7 \mathrm{mV}$ at $10 \mathrm{~mA} \mathrm{~cm}^{-2}$, with TOF reaching $18.63 \mathrm{H}_{2} \mathrm{~s}^{-1}$ at $50 \mathrm{mV}$ ) of these Pt-Ni ASs in alkaline conditions are superior to that for commercial Pt/C (Fig. 2p and q). Oh et al. [22] prepared hexapod-shaped $\mathrm{Pt}-\mathrm{Ni}$-Co alloy nanocatalysts for the efficient alkaline HER through the selective removal of the Ni@Co shell from core@double-shell Pt@Ni@Co nanostructures. Studies suggest Co precursor greatly affects the size and shape of this nanostructure. This Pt-Ni-Co catalyst shows a 10 times higher specific 

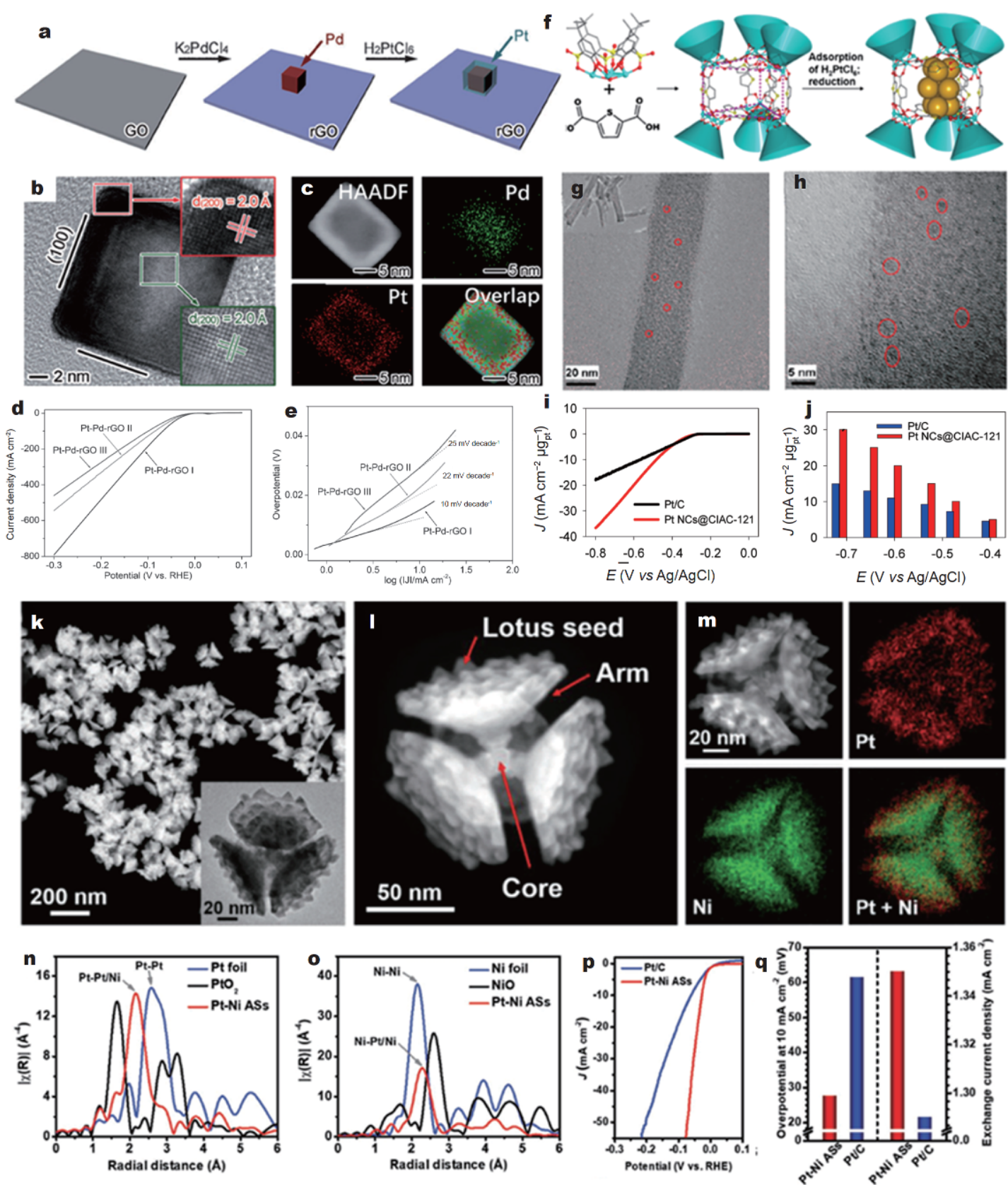

Figure 2 (a) Schematic illustration, (b) high resolution transmission electron microscopy (HRTEM), and (c) high-angle annular dark-field scanning transmission electron microscopy (HAADF-STEM) and energy dispersive spectroscopy (EDS) mapping images of Pt-Pd nanocrystal on reduced graphene oxide (rGO). (d) Linear sweep voltammetry (LSV) curves and (e) Tafel plots of Pt-Pd-rGO structures with different Pt thicknesses. The dashed lines in (e) indicate the linear regions. Adapted with permission from Ref. [10]. Copyright 2014, Wiley-VCH Verlag GmbH \& Co. (f) Illustration of the assembly of trigonal prismatic $\left\{\mathrm{Ni}_{24}\right\}$ coordination cage and the fabrication of ultrafine Pt NCs. (g, h) Transmission electron microscopy (TEM) of the Pt@CIAC-121 hybrids at different magnifications. (i) LSV curves of the Pt@CIAC- 121 and $\mathrm{Pt} / \mathrm{C}$ in $0.5 \mathrm{~mol} \mathrm{~L}^{-1} \mathrm{H}_{2} \mathrm{SO}_{4}$ for HER. (j) Comparison of current densities between Pt@CIAC-121 and Pt/C at different potentials. Adapted with permission from Ref. [16]. Copyright 2016, the American Chemical Society. (k, l) HAADF-STEM images of the Pt-Ni anisotropic superstructures (ASs). Inset in (k): TEM image of a single Pt-Ni AS. (m) HAADF-STEM and EDS elemental mapping images of a typical Pt-Ni AS. (n) Fourier transforms of extended X-ray absorption fine structure (EXAFS) spectra at Pt L3-edge. (o) Fourier transforms of EXAFS spectra of Ni K-edge. (p) LSV curves of Pt-Ni ASs and Pt/C in 1.0 mol L KOH. (q) Overpotentials at current density of $10 \mathrm{~mA} \mathrm{~cm}^{-2}$ (left) and exchange current densities (right) of Pt-Ni ASs and Pt/C. Adapted with permission from Ref. [21]. Copyright 2018, Wiley-VCH Verlag GmbH \& Co. 
activity than that of $\mathrm{Pt} / \mathrm{C}$. Shen et al. [23] prepared carbon nanofiber (CNF) arrays decorated with $\mathrm{Pt}-\mathrm{Cu}-\mathrm{Ni} \mathrm{NPs}$, which were conformally assembled on carbon felt (CF) (denoted as PtCuNi/CNF@CF) through an ambient-pressure chemical vapor deposition (CVD) process followed by a spontaneous galvanic replacement reaction. This $\mathrm{PtCuNi} /$ CNF@CF is proved to be an ideal binder-free HER eletrocatalyst on account of the high porosity, well-defined geometry shape, good electron conductivity, and particular characteristic of PtCuNi NPs in the tips of CFs.

\section{Non-noble metals and related alloys}

$\mathrm{Ni}$ has a moderate hydrogen binding energy, but metallic $\mathrm{Ni}$ itself is not an ideal HER catalyst. Ni-Fe, Ni-Co, Ni$\mathrm{Mo}, \mathrm{Ni}-\mathrm{Zn}, \mathrm{Ni}-\mathrm{W}$ and $\mathrm{Ni}-\mathrm{Cr}$ alloys have been explored for HER, and among them NiMo alloy is the most promising candidate, yet it still has difficulty to match with Pt in both activity and stability [24]. Besides alloying, hybridizing with carbon materials has also been proved to be an efficient way to boost the HER performances of transition metals. Deng et al. [25] reported nitrogendoped carbon nanotubes (NCNTs) encapsulated Fe, Co and the FeCo alloy (Fig. 3a) for HER in acid. The optimized catalysts exhibited a good HER catalytic performance (onset overpotential is $70 \mathrm{mV}$ ), which was close to that of $40 \% \mathrm{Pt} / \mathrm{C}$ catalyst (Fig. 3b). DFT calculations indicated that the optimized electronic structure and the moderate adsorption free energy of $\mathrm{H}$ atoms on the catalyst's surface promoted the HER process (Fig. $3 \mathrm{c}$ and d). Motivated by these results, they also encapsulated a uniform CoNi nanoalloy by ultrathin (1-3 layers) graphene shells (Fig. 3e-g). The optimized catalyst exhibits almost zero onset overpotential, and needs $142 \mathrm{mV}$ to deliver $10 \mathrm{~mA} \mathrm{~cm}^{-2}$ (Fig. 4h), which is comparable to that of commercial $40 \% \mathrm{Pt} / \mathrm{C}$ [26]. DFT results show that the high HER activity can be attributed to the moderate free energy of $\mathrm{H}$ adsorption and the electronic potential distribution at the graphene surface (Fig. $3 i$ and $j$ ). Additionally, the decrease of the graphene layer number and the increase of nitrogen dopant amount can improve the electron density of the graphene shells, enhancing the HER electrocatalytic performance (Fig. 3k). Tavakkoli et al. [27] decorated single-walled carbon nanotubes (SWNTs) with novel single-shell carbon-encapsulated Fe NPs (SCEINs) (Fig. 3l-m). The single carbon layer in SCEIN/SWNT would not prevent the desired contact between the reactants and vicinity of the Fe NPs, but can protect the active $\mathrm{Fe}$ core from oxidation. Thus, this SCEIN/SWNT displays superior HER catalytic properties (onset potential is about $0 \mathrm{~V}$, Tafel slope is $40 \mathrm{mV} \mathrm{dec}^{-1}$ ), which are even comparable to those of Pt in $0.5 \mathrm{~mol} \mathrm{~L}^{-1}$ $\mathrm{H}_{2} \mathrm{SO}_{4}$ (Fig. 3n).

\section{Transition metal compounds}

Because the HER process occurs on the surface of the electrocatalysts, and the surface adsorption for hydrogen is an important step, the Gibbs free energy of hydrogen adsorption $\left(\Delta G_{\mathrm{H}^{*}}\right)$ can work as an indicator to predict whether a certain material is ideally capable of catalyzing HER. When $\Delta G_{\mathrm{H}^{*}}$ has a large negative value, it suggests that the affinity between $\mathrm{H}_{\mathrm{ads}}$ and the catalyst surface is too strong, and it is difficult for the formed $\mathrm{H}_{\text {ads }}$ occupying the active site to desorb, decreasing the catalytic activity. When $\Delta G_{\mathrm{H}^{\star}}$ has a large positive value, it suggests that $\mathrm{H}_{\mathrm{ads}}$ and the catalyst surface have a weak binding, which is not conducive to the formation of $\mathrm{H}_{\mathrm{ads}}$ and transition state of hydrogen, also decreasing the catalytic activity. Therefore, an ideal $\Delta G_{\mathrm{H}^{*}}$ for HER should be close to 0 . Nørskov et al. [28] obtained a volcano-like curve by plotting $\Delta G_{\mathrm{H}^{*}}$ versus the exchange current density. The higher exchange current density suggests the better catalytic activity of the catalyst. Noble metals, such as Pt, located at the top of the volcano with $\Delta G_{\mathrm{H}^{*}}$ close to 0 , are expected to have the best catalytic activity. Besides, transition metals $\mathrm{Ni}, \mathrm{Fe}, \mathrm{Co}, \mathrm{Cu}, \mathrm{Mo}$, and $\mathrm{W}$ also have appropriate $\Delta G_{\mathrm{H}^{*}}$ values, and can form borides, carbides, nitrides, chalcogenides and phosphides as efficient HER electrocatalysts [6].

\section{Transition metal phosphides}

In 2005, Liu et al. [29] used DFT calculation to investigate the $\mathrm{Ni}_{2} \mathrm{P}(001)$ surface, and their studies suggest that the introduced $\mathrm{P}$ dilutes the surface concentration of $\mathrm{Ni}$ and avoids the inactivation of active sites caused by strong surface adsorption of $\mathrm{H}$ atoms. Besides, the formation of the Ni-P bonds disturbs the electronic states of the initial $\mathrm{Ni}$, exhibiting a [NiFe] hydrogenase-like electronic structure. Thus, $\mathrm{Ni}_{2} \mathrm{P}$ was inferred to be a highly active HER electrocatalyst. However, it was not until 2013 that this inference was verified by Schaak's group [30], and in the same year, Zhang's group [31] first reported that FeP was efficient on HER. Since then, the application of transition metal phosphides in HER began to develop [32,33]. In 2018, with core-shell ZIF-8@ZIF-67 as the precursor, Pan et al. [34] designed and synthesized a novel hybrid nanocatalyst-N-doped carbon nanotube hollow polyhedron (NCNHP) encapsulated CoP NPs by a pyrolysis-oxidation-phosphidation strategy (Fig. 4a-c). During the pyrolysis process, ZIF- 8 worked as seed, the $\mathrm{Zn}$ nodes can evaporate at high temperature, and uni- 

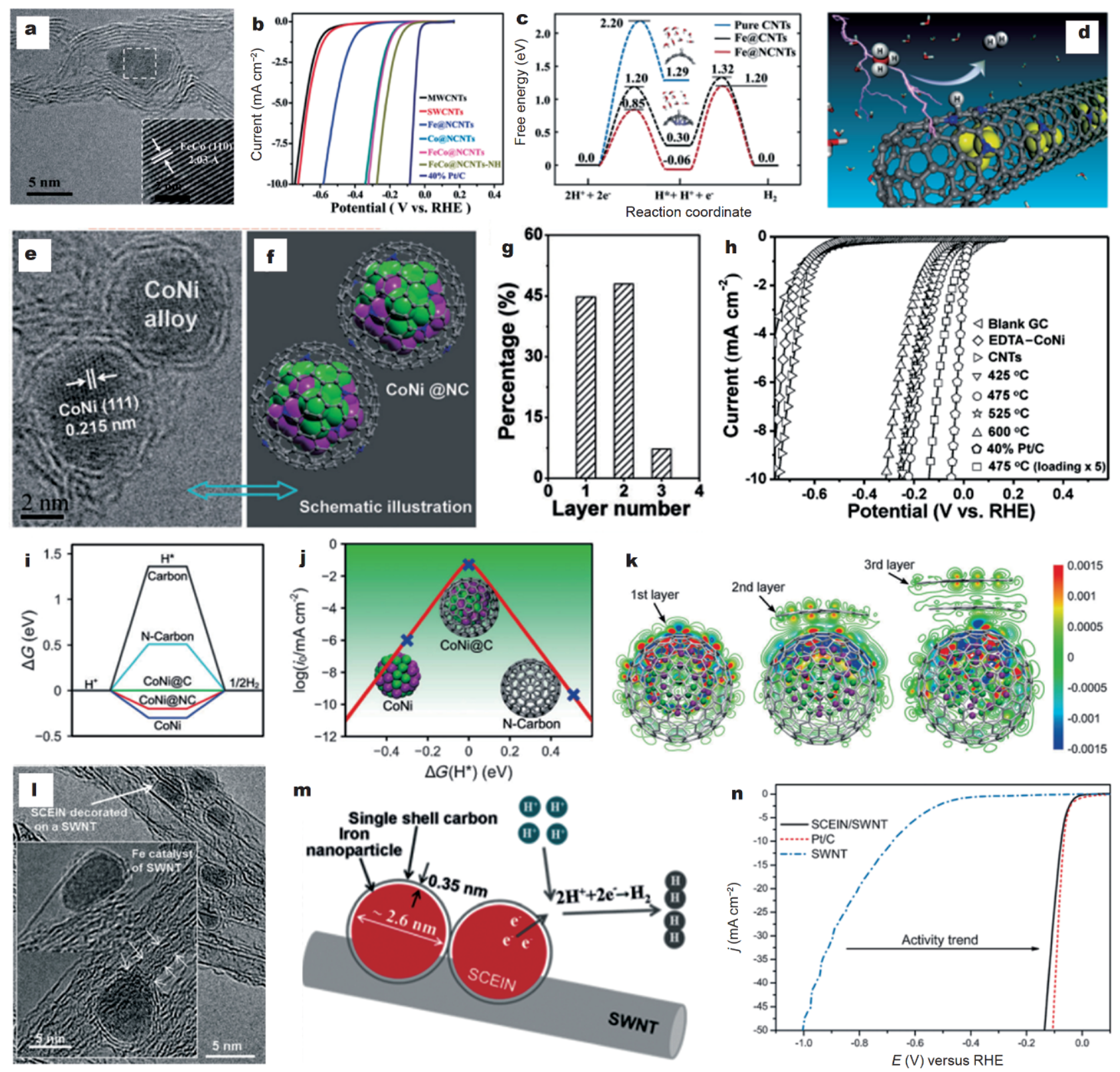

Figure 3 (a) HRTEM image of FeCo@NCNTs with the inset showing the (110) crystal plane of the FeCo nanoparticle. (b) LSV curves. (c) The free energy profiles of the Heyrovsky route. (d) A schematic representation of the HER process on the surface of Fe@NCNTs. The gray balls represent C atoms, yellow for Fe, blue for N, red for O and white for H. Reproduced with permission from Ref. [25]. Copyright 2014, the Royal Society of Chemistry. (e) HRTEM image of CoNi@NC, showing the graphene shells and encapsulated metal NPs. Inset (e): crystal (111) plane of the CoNi alloy. (f) Schematic illustration of the CoNi@NC structure shown in (e). (g) Statistical analysis of the number of layers in the graphene shells encapsulating the metal NPs in CoNi@NC. (h) HER LSV curves for CoNi@NC samples prepared at different temperatures. (i) Gibbs free energy ( $\Delta G)$ profile of the HER on various catalysts. (j) Volcano plot of the polarized current $\left(i_{0}\right)$ versus $\Delta G_{\mathrm{H}^{*}}$ for a CoNi cluster, CoNi@C, and an N-doped graphene shell (Ncarbon). (k) Redistribution of the electron densities after the CoNi clusters have been covered by 1-3 layers of graphene. The differential charge density is defined as the difference in the electron density with and without the CoNi cluster. The red and blue regions are regions of increased and decreased electron density, respectively. Adapted with permission from Ref. [26]. Copyright 2015, Wiley-VCH Verlag GmbH \& Co. (l) HRTEM image of SCEINs decorated on the sidewalls of the SWNTs; the inset shows Fe catalyst particles for the growth of the SWNTs (arrows demonstrate the SWNT). (m) Schematic representation of SCEIN/SWNT sample simplifying the HRTEM images and HER on SCEINs. (n) The polarization curves of SWNT (blue), SCEIN/SWNT (black), and Pt/C (red). The LSV curves were measured at a scan rate of $50 \mathrm{mV} \mathrm{s}^{-1}$ in $0.5 \mathrm{~mol} \mathrm{~L}^{-1} \mathrm{H}_{2} \mathrm{SO}_{4}$. Adapted with permission from Ref. [27]. Copyright 2015, Wiley-VCH Verlag GmbH \& Co. 

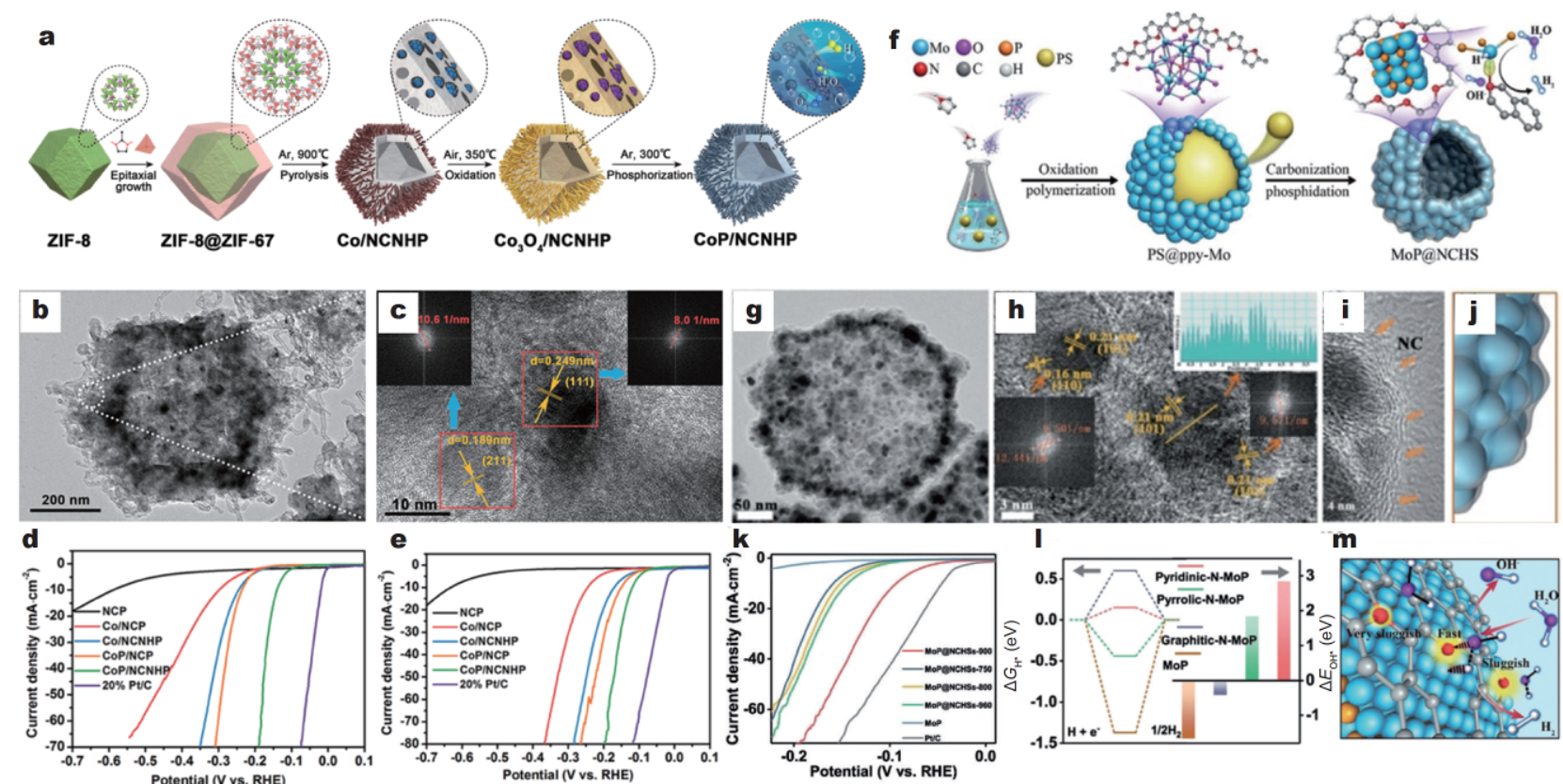

Figure 4 (a) Schematic illustration and (b, c) TEM and HRTEM of the CoP/NCNHP catalyst. Inset in (c): fast Fourier transform (FFT) of the selected area in the red box. (d, e) LSV of CoP/NCNHP and the compared samples in $0.5 \mathrm{~mol} \mathrm{~L}^{-1} \mathrm{H}_{2} \mathrm{SO}_{4}$, and $1 \mathrm{~mol} \mathrm{~L}^{-1} \mathrm{KOH}$ for HER, respectively. Adapted with permission from Ref. [34]. Copyright 2018, the American Chemical Society. (f) Schematic illustration, (g-i) TEM and HRTEM images of MoP@NCHSs-900. Insets in (h): the intensity profile along the yellow line, the FFT of the selected area of orange arrows. (j) Structural model of (i). (k) LSV curves of electrocatalysts MoP@NCHSs-T, bulk MoP, and commercial $20 \% \mathrm{Pt} / \mathrm{C}$ in $1.0 \mathrm{~mol} \mathrm{~L}^{-1} \mathrm{KOH}$. (l) $\Delta G_{\mathrm{H}^{*}}$ diagram (left) and the chemisorption energies of $\mathrm{OH}^{*}\left(\Delta E_{\mathrm{OH}^{*}}\right)$ (right). (m) The schematic of the charge density differences, average Bader charge of NC and water dissociation ability for three $\mathrm{N}$ forms based on the DFT calculation results. Blue, orange, red, silver, purple, and white balls represent Mo, P, N, C, O, and $\mathrm{H}$ atoms, respectively. Adapted with permission from Ref. [35]. Copyright 2019, Wiley-VCH Verlag GmbH \& Co.

formly dispersed Co NPs formed in the pyrolysis process of ZIF-67 shell. Besides, they found the evaporation of the $\mathrm{Zn}$ favorable for the formation of CNTs, then the mass transfer was promoted. Due to the strong synergy between the CoP NPs and NCNHP, CoP/NCNHP shows high HER (in acid and alkali) and oxygen evolution reaction (OER) performance (in alkali) (Fig. $4 \mathrm{~d}$ and e). Given to the good electrocatalytic performance, they assembled a primary battery with this catalyst, the electrocatalytic measurement suggests the full water electrolysis can be driven at $1.64 \mathrm{~V}$, and shows excellent stability ( $36 \mathrm{~h}$ without almost no attenuation of activity). DFT calculation suggests the electron transfer from NCNHP to CoP NPs can effectively increase the d-orbital density near Fermi level of Co, promoting the adsorption of hydrogen and improving the electrocatalytic performance. Meanwhile, the theoretical calculation also suggests the high oxidation resistance of the CoP/NCNHP greatly improves the stability. This work is of great significance for the design and application of transition metal phosphides/carbon based catalysts with high efficiency, stability and novel structure. In 2019, in research of Zhao et al. [35], polystyrene (PS) spheres was used as sacrificial templates, and $\mathrm{H}_{3} \mathrm{PMo}_{12} \mathrm{O}_{40} \cdot n \mathrm{H}_{2} \mathrm{O}$ was used as oxidant to initiate pyrrole (Py) monomers around PS templates to polymerize. After pyrolysis, MoP NPs were successfully encapsulated in nitrogen-doped carbon hollow spheres to form the core-shell structure of HER electrocatalyst (MoP@NCHSs) (Fig. 4f-j). This catalyst shows good HER electrocatalytic performance, it only needs $92 \mathrm{mV}$ to achieve the current density of $10 \mathrm{~mA} \mathrm{~cm}^{-2}$ (Fig. 4k). And the studies suggest that the synergistic effect between MoP and pyridine $\mathrm{N}$ effectively promotes the alkaline HER process, and the interaction between them greatly increases the electron density on the NCHSs carrier, thus accelerating HER; besides these, the d-band center of Mo atom at the interface between pyridine $\mathrm{N}$ and MoP decreases, weakening the Mo- $\mathrm{H}_{\text {ads }}$ bond, and inhibiting the strong adsorption of $\mathrm{OH}^{*}$ by pyridine $\mathrm{N}$ (Fig. $4 \mathrm{l}$ and $\mathrm{m}$ ).

The theoretical calculation results suggest that $\mathrm{P}$ in transition metal phosphides plays a key role in the HER process. On the one hand, the electronegative $\mathrm{P}$ atoms in phosphides can attract electrons transferred from metals, 
making the $\mathrm{P}$ atoms negatively charged and the metal atoms positively charged. The $\mathrm{P}$ with negative charge not only works as an alkaline group to trap the protons produced in the process of hydrogen precipitation, but also promotes the dissociation of hydrogen, thus avoiding the long-time occupation of the active sites owing to the strong adsorption of hydrogen. Wang's group [36] gave an elaboration on the effect of $\mathrm{P}$ on the hydrogen evolution. Their study suggests that the P atoms in MoP can work as "hydrogen deliverers", and P can bond with hydrogen at low coverages but release hydrogen at high coverages. The special function of $\mathrm{P}$ atoms can create rich active sites in MoP, making the phosphides very suitable for HER. Besides, $\mathrm{P}$ atoms can also improve the corrosion resistance of phosphides especially in acid. The undesired dissolution becomes thermodynamically unfavorable because of the $\mathrm{P}$ atoms. At the same time, the surface oxidation to form phosphate can further protect the phosphides from dissolution in the electrolyte. Generally, increasing the atomic percentage of $\mathrm{P}$ can produce more HER active sites and improve the stability of the phosphides. However, the delocalization of electrons on the metal is greatly limited by the highly electronegative $\mathrm{P}$ atoms, impairing the electrical conductivity. Thus, it is important to balance these two aspects by adjusting the atomic ratio of $\mathrm{P}$ and the metal.

Recently, some research results [37,38] suggest there exists only one kind of electron transfer in single metal phosphides, producing only one kind of active sites, which is not efficient enough for HER. Introducing a foreign metal can provide more kinds of electron transfer, and produce more active sites; also, there may exist synergistic and complementary effect between different atoms, thus bi-metallic and even multi-metallic phosphides usually show better HER electrocatalytic performances with respect to single-metallic counterparts. Tang et al. [39] developed ternary $\mathrm{Fe}_{x} \mathrm{Co}_{1-x} \mathrm{P}$ nanowire array on carbon cloth $\left(\mathrm{FexCo}_{1-x} \mathrm{P} / \mathrm{CC}\right)$ for electrocatalytic HER. Their studies suggest that the amount of Fe strongly affect the HER activity. Electrocatalytic test suggests that $\mathrm{Fe}_{0.5} \mathrm{Co}_{0.5} \mathrm{P} / \mathrm{CC}$ has the best activity $(37 \mathrm{mV}$ at $10 \mathrm{~mA} \mathrm{~cm}{ }^{-2}$ ). DFT calculations suggest that the replacement of Co by Fe in CoP optimizes $\Delta G_{\mathrm{H}^{*}}$ on the catalyst surface. Similarly, the study of Li et al. [40] suggests that a proper doping ratio of $\mathrm{Fe}$ in $\mathrm{Ni}_{2} \mathrm{P}$ can also significantly improve the HER performance. The research of Liang et al. [41] also suggests that the HER electroactivity of MoP can be remarkably enhanced by the proper introduction of $\mathrm{Fe}$. Li et al. [42] synthesized rGO incorporating Codoped nickel phosphides $\left(\mathrm{Ni}_{2-x} \mathrm{Co}_{x} \mathrm{P}\right)$. The doping of Co and the hybridization with rGO effectively improve the HER electrocatalytic performance within the $\mathrm{pH}$ range of $0-14$, by virtue of the enriched active sites on the catalyst surface and the accelerated charge transfer. DFT calculations suggest the Co doping leads to the moderate adsorption of atomic hydrogen and easy desorption of the formed $\mathrm{H}_{2}$. Man et al. [43] prepared $\mathrm{Ni}_{2} \mathrm{P}$ NPs doped with transition metals ( $\mathrm{Fe}, \mathrm{Co}, \mathrm{Mn}$ and $\mathrm{Mo}$ ) for electrocatalytic HER. Their results suggest that Mo-doped $\mathrm{Ni}_{2} \mathrm{P}$ shows the best HER electrocatalytic activity because of the largest degree of d-electron delocalization.

\section{Transition metal sulfides}

Hydrodesulfurization (HDS) proceeds via a similar pathway to that of HER, both including a reversible surface adsorption/desorption of hydrogen, thus broadening the scope of the search for new HER catalysts. Sulfides, especially $\mathrm{MoS}_{2}$, are widely used as HDS catalysts to remove sulfur from natural gas and fuels, and have proved to be efficient HER electrocatalysts [44]. Fe [45], Co [46-48], Ni [49] and W [50-53] could also form sulfides that are applicable to HER.

As early as 1977, Tributsch et al. [54] suggested that bulk natural crystals of $\mathrm{MoS}_{2}$ might show HER electrocatalytic activity, yet its potential as efficient HER electrocatalyst was not fully unveiled until 20 years later. In 2005, Hinnemann et al. [55] suggested that the basal plane of $\mathrm{MoS}_{2}$ is catalytically inert, while the true active species are the sulfidated Mo-edges, on the basis of analyzing the free energy of hydrogen using DFT calculations. Two years later, this inference was proved experimentally by Jaramillo et al. [56]. Now, this notion has been widely accepted among the researchers. Therefore, subsequent efforts have been devoted to maximizing the exposure of such edge sites, among which one efficient strategy is nano-structuring [57]. Kong et al. [58] maximized the exposure of edges by growing $\mathrm{MoS}_{2}$ and $\mathrm{MoSe}_{2}$ thin films with vertically aligned layers. Their studies suggest that through this kinetically controlled rapid growth strategy, the edge-terminated structure can be synthesized on a diverse range of substrates. Kibsgaard et al. [59] engineered the $\mathrm{MoS}_{2}$ surface structure which preferentially expose the edge sites by fabricating contiguous large-area thin films of a highly ordered doublegyroid $\mathrm{MoS}_{2}$ bicontinuous network with nanosized pores. The high surface curvature of this mesostructure of the catalyst helps to expose a large fraction of edge sites and provide high surface area, leading to an excellent HER electrocatalytic activity. Wang et al. [60] used selective steam etching to improve the density of active edge sites 
on $\mathrm{MoS}_{2}$ basal plane. They suggest that the temperature greatly affects the etched structure, and $\mathrm{MoS}_{2}$ basal planes with $1 \mathrm{D}$ nano-channels, 2D in-plane triangular pits and $3 \mathrm{D}$ vertical hexagonal cavities can be created by increasing the temperature. The studies indicate that the surface free energy barrier can be effectively decreased by the extensive created active edges existing on the $\mathrm{MoS}_{2}$ basal plane, thus improving the HER electrocatalytic activity.

Recently, a pioneering strategy of introducing $\mathrm{S}$ vacancies into the basal plane has been proposed, which can also improve the electrocatalytic performance. Li et al. [61] firstly introduced S vacancies and strain activated to activate and optimize the basal plane of monolayer $2 \mathrm{H}$ MoS. Their results show that creating and straining $S$ vacancies in the basal plane is efficient for optimizing the electronic structure of $\mathrm{MoS}_{2}$ to enhance the HER activity. New bands in the gap near the Fermi level can be produced by $S$ vacancies, and these states are localized around the $S$ vacancies, and hydrogen adsorption takes place on these new gap states. With more $S$ vacancies, the number of gap states increases and the bands shift towards the Fermi level. In addition, introducing tensile strain makes the positions of these new bands further move towards the Fermi level, which narrows the band gap and increases the number of gap states around the Fermi level, leading to the increased adsorption strength on $S$ vacancy site. Later, the HER kinetic data for both unstrained and strained $S$ vacancies on the basal plane of $\mathrm{MoS}_{2}$ monolayers were studied through scanning electrochemical microscopy. Their study suggests that the strained $S$ vacancy has a 4 times higher electron-transfer rate than that of the unstrained S vacancy. Besides, about $2 \%$ uniaxial tensile strain increases almost four folds the electron-transfer rate constant $\left(k_{\mathrm{sv}}{ }^{0}=1.0 \times 10^{-3} \mathrm{~cm} \mathrm{~s}^{-1}\right)$, confirming that the HER kinetics of $\mathrm{S}$ vacancies in $\mathrm{MoS}_{2}$ indeed can be accelerated by tensile elastic strain [62]. Tsai et al. [63] introduced electrochemical desulfurization to generate $\mathrm{S}$ vacancies on the $\mathrm{MoS}_{2}$ basal plane. In the electrochemical desulfurization process, the $S$ atoms in the basal plane are hydrogenated into $\mathrm{H}_{2} \mathrm{~S}$ and then removed to form the $S$ vacancies. The HER activity can be significantly improved by varying the extent of desulfurization and the concentration of $S$ vacancies due to the changed applied desulfurization potential and duration. Li et al. [64] reported the grain boundary may also provide some catalytic activity for HER. Zhu et al. [65] reported that domain boundaries in the basal plane of monolayer $\mathrm{MoS}_{2}$ can act as active sites for HER. Their studies suggest the multi-hierarchy design on the $2 \mathrm{H}-2 \mathrm{H}$ domain boundaries and $2 \mathrm{H}-1 \mathrm{~T}$ phase boundaries can greatly improve the HER performances (activity, stability and universality in both acid and alkali).

\section{Transition metal selenides}

Se locates in the same main group as $S$ does in the periodic table; therefore, metal selenides may possess great potential for HER as well. In 2012, NiSe was prepared for HER by Gao et al. [66]. Zhou et al. [67] demonstrated that commercial $\mathrm{Ni}$ foam can be used as the starting material to fabricate a robust porous $\mathrm{NiSe}_{2}$ electrocatalyst by simple acetic acid treatment and thermal selenization in Ar atmosphere. X-ray photoelectron spectroscopy (XPS) and EDS analysis suggest that a small fraction of elemental Se is detected on the surface, and theoretical calculations suggest the adsorbed Se monomers or dimers on the surface could optimize $\Delta G_{\mathrm{H}^{*}}$. Facilitated by the large electrochemically active surface and good electrical conductivity, this $\mathrm{NiSe}_{2}$ exhibits good catalytic activity that approaches that of the benchmark Pt. Kong et al. [68] developed $\mathrm{CoSe}_{2}$ NPs grown on carbon fiber paper, which exhibit an excellent HER activity $(\sim 180 \mathrm{mV}$ at $100 \mathrm{~mA} \mathrm{~cm}^{-2}$, Tafel slope is $\sim 40 \mathrm{mV} \mathrm{dec}^{-1}$ ). Studies on molybdenum selenide $\left(\mathrm{MoSe}_{2}\right)$ and tungsten selenide $\left(\mathrm{WSe}_{2}\right)$ as HER catalysts are not as extensive as those on $\mathrm{MoSe}_{2}$ and $\mathrm{WSe}_{2}$. Through periodic DFT, Tsai et al. [69] studied the structures of the Mo/W-edges and the Seedges under HER conditions and their differential hydrogen adsorption free energies. Mo-edge and Se-edge on both $\mathrm{MoSe}_{2}$ and $\mathrm{WSe}_{2}$ are found to be the predominant active facets, and are predicted to have HER activities comparable or even superior to that of $\mathrm{MoS}_{2}$. The design optimization for $\mathrm{MoSe}_{2}$ and $\mathrm{WSe}_{2}$, which could maximize the exposure of edge sites, are also efficient for improving HER performances. Coupling with highly conductive carbon materials can help to expose more active sites and accelerate the electron transfer process. Liu et al. [70] synthesized $\mathrm{MoSe}_{2}$ nanostructures anchored on rGO NSs $\left(\mathrm{MoSe}_{2} / \mathrm{rGO}\right)$ for HER. The rich defects in the $\mathrm{MoSe}_{2}$ layers and high electrical conductivity of rGO are in favour of the exposure of active edge sites and electron transfer, leading to the excellent HER performance. Tang et al. [71] prepared $\mathrm{MoSe}_{2} \mathrm{NSs}$ and $\mathrm{MoSe}_{2}$ /graphene hybrids for HER. Both the experimental and theoretical studies indicate that $\mathrm{MoSe}_{2}$ has a great potential for HER, and even may exceed $\mathrm{MoS}_{2}$. Yin et al. [72] simultaneously regulated the phase and disorder to maximize the HER activity of $\mathrm{MoSe}_{2}$. The synthesized, partially crystallized $1 \mathrm{~T}-\mathrm{MoSe}_{2}$ NSs show an excellent HER performance. Through structural and defect characterizations, they concluded that the synergistic regulations of both phase 
and disorder in this $1 \mathrm{~T}-\mathrm{MoSe}_{2}$ NSs facilitated the HER process.

\section{Transition metal carbides}

Carbides (such as vanadium carbide [73], nickel carbide [74], niobium carbide [75] and tantalum carbide [75]) have been reported for efficient electrocatalytic HER, and molybdenum carbide and tungsten carbide are two typical examples. As early as 1970s, the studies of Levy [76] and Bennett [77] suggested that introducing carbon to tungsten (named tungsten carbide) can make the electronic density of states (DOS) more resemble that of $\mathrm{Pt}$ near the Fermi level, and tungsten carbide therefore should have potential for HER. To some extent, substantially reducing the particle sizes to nanoclusters or even single atoms, would be effective to obtain a high HER activity. Xu et al. [78] synthesized ultrasmall tungsten carbide nanoclusters/NPs to achieve the ultrahigh catalytic activities (Fig. 5a-c). They selected an RHO-type zeolitic metal azolate framework MAF-6 with large na- a Cage-confinement

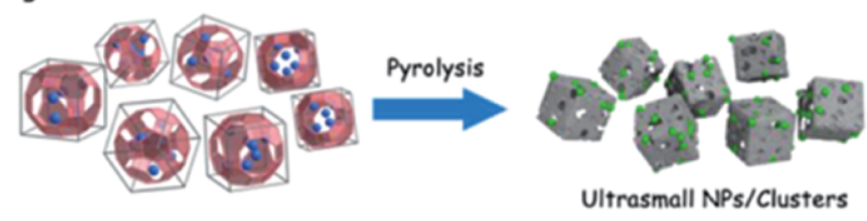

Non-confinement

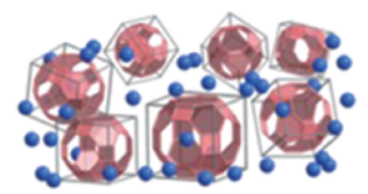

\section{b}
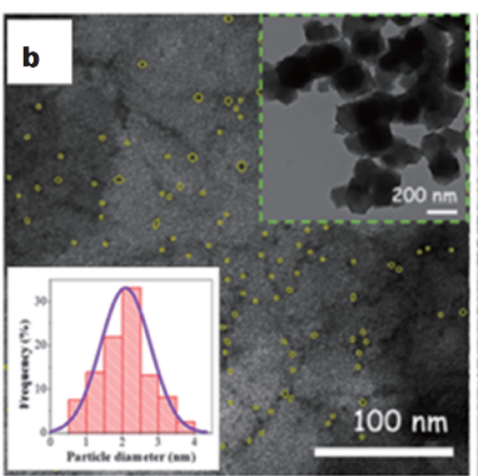

d

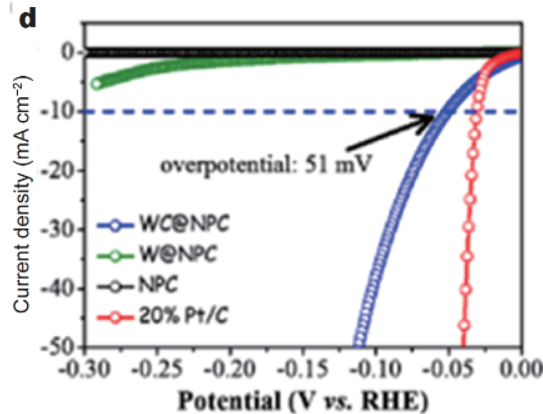

e f

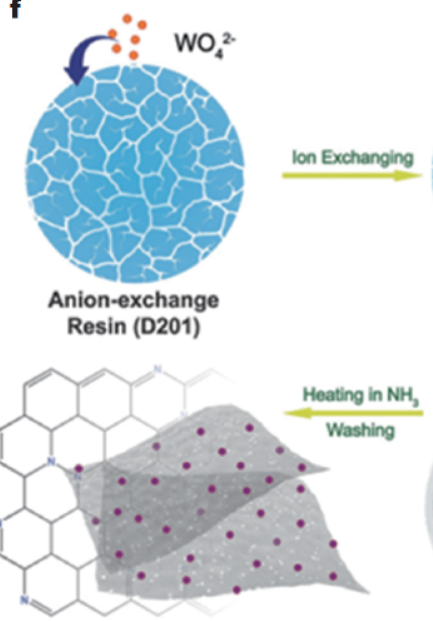

WN@N-Rich Porous Graphene-Like Carbon Nanosheets

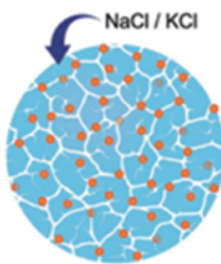

D201-WO ${ }^{2 .}$

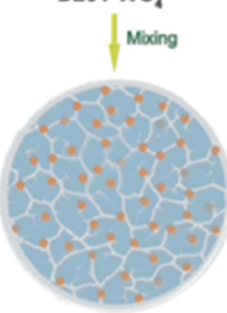

D201-WO ${ }_{4}^{2} \cdot \mathrm{NaCl} / \mathrm{KCl}$
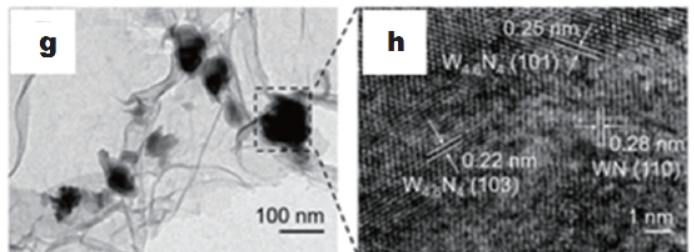

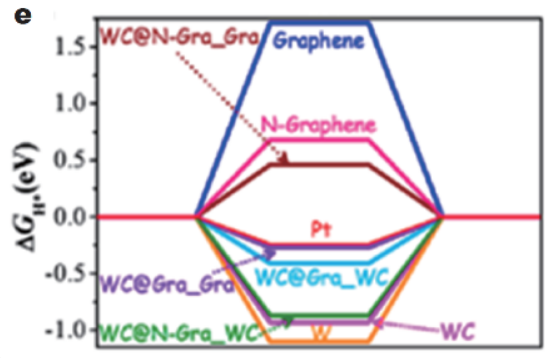

Reaction coordination

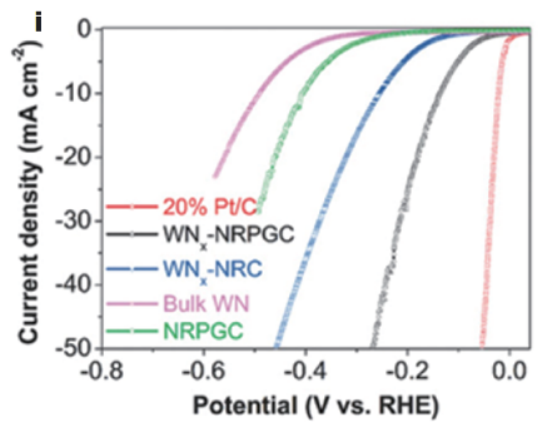

Figure 5 (a) Comparison between the cage-confinement and non-confinement pyrolysis methods for synthesizing nanocatalysts. (b) TEM, (c) HRTEM of tungsten carbide protected embedded in N-doped nanoporous carbon (denoted as WC@NPC) (inset: TEM image under lower magnification and particle-size distribution). (d) HER LSV curves in $0.5 \mathrm{~mol} \mathrm{~L}^{-1} \mathrm{H}_{2} \mathrm{SO}_{4}$. (e) Free energy of $\mathrm{H}^{*}$ adsorption on different surfaces by DFT calculation. Adapted with permission from Ref. [78]. Copyright 2017, the American Chemical Society. (f) Procedure for the synthesis of the tungsten nitride $\left(\mathrm{WN}_{x}\right)$ NPs decorated on nitrogen-rich porous graphene-like carbon nanosheets (denoted as $\mathrm{WN}_{x}-\mathrm{NRPGC}$ ) composite. (g) TEM, and (h) HRTEM images of the $\mathrm{WN}_{x}$-NRPGC composite. (i) LSV curves of the samples in $0.5 \mathrm{~mol} \mathrm{~L}^{-1} \mathrm{H}_{2} \mathrm{SO}_{4}$ at a scan rate of $5 \mathrm{mV} \mathrm{s}$. Adapted with permission from Ref. [92]. Copyright 2018, Wiley-VCH Verlag GmbH \& Co. 
nocages and small apertures to confine the $\mathrm{W}(\mathrm{CO})_{6}$ metal precursor. After pyrolysis at high temperature, tungsten carbide nanoclusters/NPs could be obtained, which have moderated $\mathrm{H}$ adsorption free energy and exhibit excellent HER performance in $0.5 \mathrm{~mol} \mathrm{~L}^{-1} \mathrm{H}_{2} \mathrm{SO}_{4}(51 \mathrm{mV}$ at $10 \mathrm{~mA} \mathrm{~cm}^{-2}$, Tafel slope is $49 \mathrm{mV} \mathrm{dec}^{-1}$ ) (Fig. $5 \mathrm{~d}$ and e).

Similar to tungsten carbides, intensive attention was also attracted on molybdenum carbides. Kim et al. [79] synthesized $\mathrm{Mo}_{2} \mathrm{C}, \mathrm{Fe}_{3} \mathrm{C}$, and WC NPs loaded on rGO substrate for HER. Among these carbides, $\mathrm{Mo}_{2} \mathrm{C} / \mathrm{rGO}$ shows the best HER activity. Ma et al. [80] encapsulated uniform $\mathrm{Mo}_{2} \mathrm{C}$ NPs (with size below $3 \mathrm{~nm}$ ) with ultrathin graphene shells (1-3 layers). The cooperative/synergistic effects among $\mathrm{Mo}_{2} \mathrm{C}$, graphene shells, and the doped $\mathrm{N}$ contribute to the excellent HER performance in acidic media (a low onset potential $(6 \mathrm{mV})$, a small Tafel slope $\left(41 \mathrm{mV} \mathrm{dec}{ }^{-1}\right)$, a large exchange current density $\left(0.179 \mathrm{~mA} \mathrm{~cm}^{-2}\right)$ and a good stability $\left.(12 \mathrm{~h})\right)$.

However, NPs are not an ideal form owing to the eventual activity loss when used in pristine form and the oxide-passivation in HER condition. Ko et al. [81] synthesized WC nanowalls for HER. No oxidation took place even after prolonged cycling tests (10,000 cycles) in the HER environment, suggesting the superior stability due to the highly crystalline and the smooth surface of the pristine WC nanowalls. Wu et al. [82] prepared mesoporous molybdenum carbide $\left(\mathrm{MoC}_{x}\right)$ nano-octahedrons composed of ultrafine nanocrystallites, which exhibit remarkable HER electrocatalytic performances in both acid and alkali. Humagain et al. [83] reported scalable synthesis of porous $\mathrm{Mo}_{2} \mathrm{C}$ nanostructures. The $\mathrm{Mo}_{2} \mathrm{C}$ catalyst exhibits an excellent HER activity ( 35 and $60 \mathrm{mV}$ at 0 and $10 \mathrm{~mA} \mathrm{~cm}^{-2}, 60 \mathrm{mV}$ at $100 \mathrm{~mA} \mathrm{~cm}^{-1}$ ) and stability $\left(>100 \mathrm{~h}\right.$ at 10 and $\left.100 \mathrm{~mA} \mathrm{~cm}^{-1}\right)$.

\section{Transition metal nitrides}

Transition metal nitrides have also attracted much attention as efficient HER electrocatalysts for their properties similar to noble metals. Many transition metal nitrides have been reported to show good HER properties, such as WN [84], $\mathrm{Ni}_{3} \mathrm{~N}[85,86], \mathrm{MoN}$ [87], $\mathrm{Co}_{x} \mathrm{~N}$ [88], $\mathrm{Fe}_{x} \mathrm{~N}$ [89]. Yu et al. [90] synthesized various porous metallic nitrides on different substrates for HER in alkaline media. Compared with $\mathrm{Fe}_{4} \mathrm{~N}$ and $\mathrm{Ni}_{3} \mathrm{~N}, \mathrm{CoN}$ is the best single-metal nitride for HER in $1 \mathrm{~mol} \mathrm{~L}^{-1} \mathrm{KOH}$ $\left(95 \mathrm{mV}\right.$ at $100 \mathrm{~mA} \mathrm{~cm}^{-2}$, and $212 \mathrm{mV}$ at $100 \mathrm{~mA} \mathrm{~cm}^{-2}$ ). In addition, introducing $\mathrm{Ni}$ into $\mathrm{CoN}$ to form bi-metallic nitrides of NiCoN would further improve the HER activity $\left(48 \mathrm{mV}\right.$ at $100 \mathrm{~mA} \mathrm{~cm}^{-2}$, and $149 \mathrm{mV}$ at $100 \mathrm{~mA} \mathrm{~cm}^{-2}$ ). Titanium nitride (TiN), which shows good conductivity and corrosion resistance in aqueous solutions, is also considered as a promising catalyst for HER. Han et al. [91] directly synthesized single-crystalline TiN nanowires used a CVD method. The TiN nanowires are proved to be an efficient HER catalyst $(92 \mathrm{mV}$ at $1 \mathrm{~mA} \mathrm{~cm}{ }^{-2}$, Tafel slope, $54 \mathrm{mV} \mathrm{dec}^{-1}$ ) with a good chemical stability $(20,000$ cycles and $100 \mathrm{~h})$ in acid. Zhu et al. [92] coupled tungsten nitride $\left(\mathrm{WN}_{x}\right)$ with nitrogen-rich porous graphene-like carbon to optimize its HER activity. Benefiting from the nanostructured $\mathrm{WN}_{x}$ and the synergy, this catalyst exhibits a remarkable electrocatalytic performance (Fig. 5f-i).

\section{Transition metal borides}

Compared with the above-mentioned compounds, the reports with transition metal borides as active HER electrocatalyst do not attract so much attention. Actually, as early as 1992, Los and Lasia [93] used amorphous nickel boride for alkaline HER, but since then borides as active HER has not obtained considerable development which may be due to the difficult synthesis process [94]. Masa et al. [95] used amorphous cobalt boride $\left(\mathrm{Co}_{2} \mathrm{~B}\right)$ as an efficient alkaline HER electrocatalyst. Lu et al. [96] synthesized CoB NPs on $\mathrm{CoO}$ nanowire (CoB@CoO nanoarray), which displays high activity ( $102 \mathrm{mV}$ to reach $50 \mathrm{~mA} \mathrm{~cm}^{-2}$ ) and durability (the current density only degrades $<17 \%$ after $20 \mathrm{~h}$ electrolysis) in $1.0 \mathrm{~mol} \mathrm{~L}^{-1}$ $\mathrm{KOH}$. Zhang et al. [97] electrolessly plated $\mathrm{NiB}_{x}$ films for the HER in a wide $\mathrm{pH}$ range. The particle size and morphology of $\mathrm{NiB}_{x}$ are greatly affected by the atomic ratio of $\mathrm{B}$ to $\mathrm{Ni}$, thus producing different electrocatalytic performances. $\mathrm{NiB}_{0.54}$ (atomic ratio of $\mathrm{Ni}$ to $\mathrm{B}$ is $1: 0.54$ ) film is the optimal electrocatalyst with 45,54 and $135 \mathrm{mV}$ to reach the current density of $10 \mathrm{~mA} \mathrm{~cm}^{-2}$ in $0.5 \mathrm{~mol} \mathrm{~L}^{-1}$ $\mathrm{H}_{2} \mathrm{SO}_{4}, 1.0 \mathrm{~mol} \mathrm{~L}^{-1}$ phosphate buffer solution (PBS, pH 7) and $1.0 \mathrm{~mol} \mathrm{~L}^{-1} \mathrm{KOH}$. Until 2012, molybdenum boride (MoB) was first reported as active HER catalysts by Vrubel et al. [98]. Park et al. [99] reported the synthesis and the HER electrocatalytic studies of $\mathrm{Mo}_{2} \mathrm{~B}, \alpha-\mathrm{MoB}, \beta$ $\mathrm{MoB}$, and $\mathrm{MoB}_{2}$, and their results suggest the HER activity increases with the increase of boron content. Gupta et al. [100] synthesized Co-Ni-B nanocatalysts for electrocatalyzing HER in a wide $\mathrm{pH}$ range. The results suggest the molar ratio of $\mathrm{Ni}$ affects the activity greatly. $\mathrm{Co}-30 \mathrm{Ni}-$ B (with $30 \% \mathrm{Ni}$ ) has the best HER catalytic activity $\left(170 \mathrm{mV}\right.$ at $10 \mathrm{~mA} \mathrm{~cm}^{-2}, \mathrm{pH} 7,133 \mathrm{mV}$ at $10 \mathrm{~mA} \mathrm{~cm}^{-2}$, $\mathrm{pH}$ 14). Xu et al. [101] deposited CoNiB NPs on Ni foam (CoNiB@NF), also showing good activity towards the HER. 


\section{STRUCTURE-ACTIVITY RELATIONSHIP OF NANOCATALYSTS IN ELECTROCHEMICAL HER}

\section{Modulation on microscopic structures (phase, size, and morphology)}

The changes of chemical and structural parameters on microscopic structure (such as phase composition, size, shape/morphology) would also lead to changes in chemistry and structure on the surface, and would profoundly affect the catalytic performances, as the heterogeneous catalysis processes occurred on the surface [102]. Pan et al. [103] synthesized three crystalline phases of nickel phosphide $\left(\mathrm{Ni}_{12} \mathrm{P}_{5}, \mathrm{Ni}_{2} \mathrm{P}, \mathrm{Ni}_{5} \mathrm{P}_{4}\right)$ (Fig. 6a-c), and found all of these catalysts are efficient for acidic HER, but the crystalline phase shows great effect on the HER electrocatalytic performance. The electrocatalytic activity follows the order of $\mathrm{Ni}_{5} \mathrm{P}_{4}>\mathrm{Ni}_{2} \mathrm{P}>\mathrm{Ni}_{12} \mathrm{P}_{5}$ (Fig. 6d), which can be ascribed to the different electronic properties of $\mathrm{Ni}$ and group effect of $\mathrm{P}$-the highest positive charged $\mathrm{Ni}$ and the strongest group effect $\mathrm{P}$ in $\mathrm{Ni}_{5} \mathrm{P}_{4}$ led to the best HER performance. And their later research [104] suggests this crystalline phase effect also exists in cobalt phosphide materials. To give a clear comprehension on the effect of the crystalline phase on the HER performance, Callejas et al. [105] compared the HER performances of the different phase compositions of $\mathrm{Co}_{2} \mathrm{P}$ and $\mathrm{CoP}$ NPs with the same morphology and size (thus minimizing contributions of morphologies to the HER) (Fig. 6e and f). Their results show that CoP gives a better HER catalytic activity than $\mathrm{Co}_{2} \mathrm{P}$ because of the higher density of active sites introduced by the increased $\mathrm{P}$ contents in CoP (Fig. 6g). Even with the same atomic composition, the HER performance of transition metal chalcogenides is significantly affected by the phase. As widely recognized, 1Tphase $\mathrm{MoS}_{2}$ or 1T-phase WS 2 shows superior HER catalytic performances than the corresponding $2 \mathrm{H}$-phase by virtue of the enhanced charge transfer kinetics [50,106108].

Nanocatalysts with different shapes have different crystallographic shapes, packing manners, densities and even electronic states, which essentially affect the catalytic performance [102]. On the other hand, HER involves processes among three phases (gas/water/solid). During the HER process, the formed $\mathrm{H}_{2}$ bubbles may aggregate on the catalysts' surface, hindering the liquid mass transport and electron transfer, decreasing the number of exposed active sites, severely reducing the HER electrocatalytic performance. "Superaerophobicity" is an ideal surface state, which usually can be achieved by the for- mation of array architecture [109]. The study of Wang et al. [110] suggested that the morphology of the electrocatalyst surface greatly affect the equilibrium state of formation/detachment of the gas bubbles. Lu et al. [111] reported that $\mathrm{MoS}_{2}$ nanostructures with vertically aligned $\mathrm{MoS}_{2}$ nanoplatelets show a under-water "superaerophobic" surface, making the as-formed $\mathrm{H}_{2}$ bubbles quickly driven off, and leading to a constant working area, thus greatly promoting the HER performance. Similarly, Li et al. [9] fabricated pine-shaped Pt nanostructures with under-water superaerophobicity, which showed a much higher HER performance than Pt nanospheres and flat electrodes.

\section{Modulation on electronic structures}

Introduction of foreign atoms into transition metal compounds can help modulate the electronic structures to improve the HER performances, and the introduced atoms can be cations or anions [112,113]. Wang et al. [114] investigated the HER performance of the cobaltdoped $\mathrm{FeS}_{2} \mathrm{NSs} / \mathrm{CNTs}\left(\mathrm{Fe}_{0.9} \mathrm{Co}_{0.1} \mathrm{~S}_{2} / \mathrm{CNT}\right)$, and they believed that doping metal atoms can effectively modify the electronic structure, thus optimizing the $\Delta G_{\mathrm{H}^{*}}$ on the catalyst surface, accelerating the HER process. Hou et al. [115] constructed porous cobalt phosphorus selenide nanosheets (Fig. 6h-l) for HER, which showed good catalytic performances in alkaline media (150 and $180 \mathrm{mV}$ at 10 and $20 \mathrm{~mA} \mathrm{~cm}^{-2}$, respectively) (Fig. $6 \mathrm{~m}$ ). Theoretical calculations suggest that the replacement of Se around the vacancies by $\mathrm{P}$ atoms tunes the electronic structure of cobalt selenide, and optimizes the charge transfer and hydrogen desorption, thus promoting the kinetics (Fig. 6n).

Non-metal doping can also tune the electronic structures of electrocatalysts. Kibsgaard and Jaramillo [116] doped S into MoP, forming molybdenum phosphosulfide $(\mathrm{MoP} \mid \mathrm{S})$. The catalyst shows an improved HER activity over pure MoP; the team believed that S and P can optimize the electronic structure to enhance the electrocatalytic activity. Cabán-Acevedo et al. [117] suggested the doping of phosphorus on cobalt sulfides to form cobalt phosphosulfide (CoPS) can change the $\mathrm{S}_{2}{ }^{2-}$ to $(\mathrm{SP})^{3-}$ dumbbells (Fig. 6o-r), which increases the surface electronic density, resulting in an optimized hydrogen adsorption, and thus enhancing HER process (Fig. $6 \mathrm{~s}$ and $\mathrm{t}$ ). Hong et al. [118] also synthesized a self-supporting nanoporous cobalt phosphosulfate $(\mathrm{CoP} \mid \mathrm{S})$ electrocatalyst for HER in alkaline and acidic media, and their theoretical studies confirm the substitution of $\mathrm{P}$ by $\mathrm{S}$ can modify the electronic structures of the catalyst, thereby improv- 

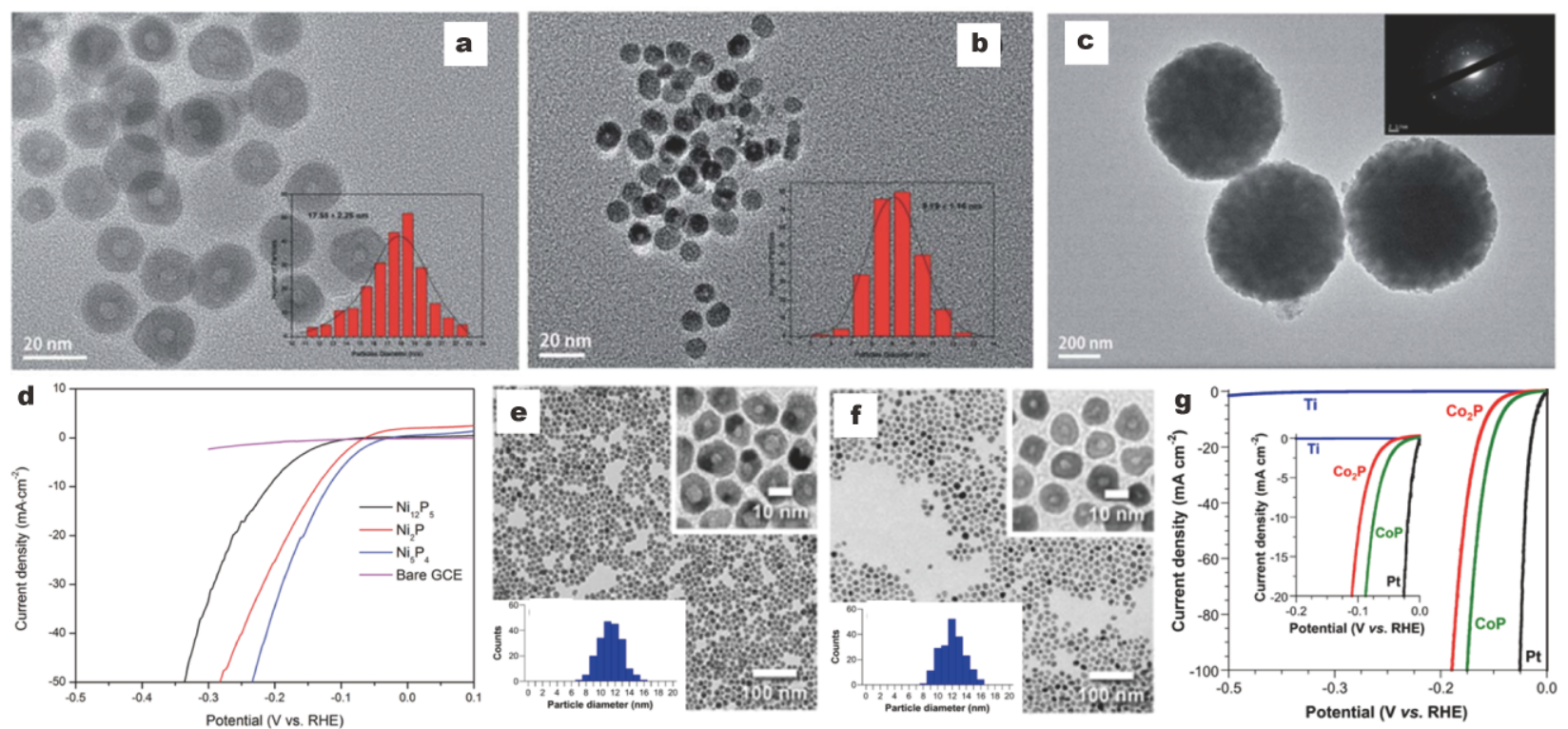

h
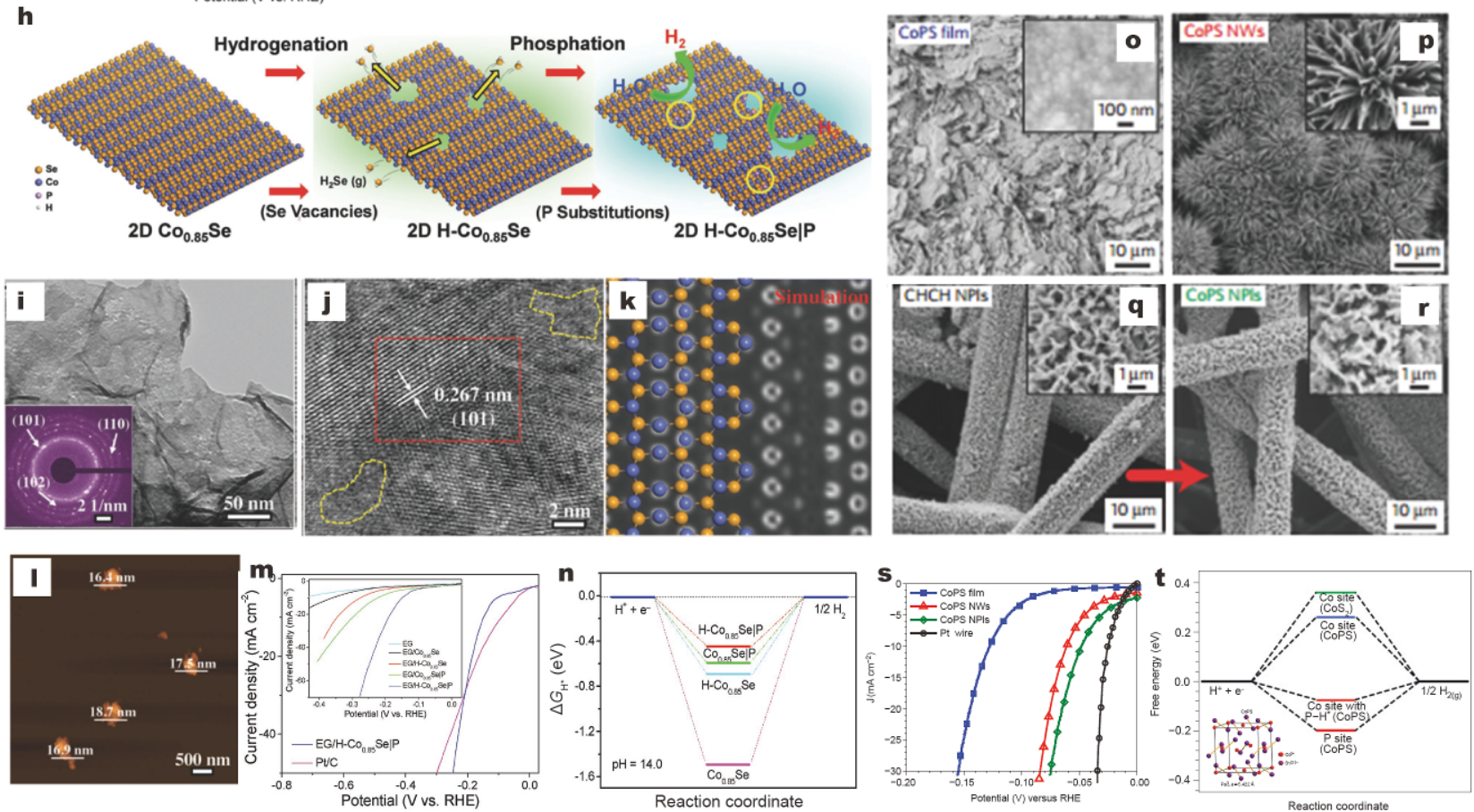

Figure 6 TEM images of nickel phosphide nanocrystals with different phases: (a) $\mathrm{Ni}_{12} \mathrm{P}_{5}$, (b) $\mathrm{Ni}_{2} \mathrm{P}$, and (c) $\mathrm{Ni}_{5} \mathrm{P}_{4}$. The size distributions of $\mathrm{Ni}_{12} \mathrm{P}_{5}$ and $\mathrm{Ni}_{2} \mathrm{P}$ are shown in the insets in (a) and (b). The selected area electron diffraction (SAED) pattern of $\mathrm{Ni}_{5} \mathrm{P}_{4}$ is shown in the inset in (c). (d) LSV curves of the samples in $0.5 \mathrm{~mol} \mathrm{~L}^{-1} \mathrm{H}_{2} \mathrm{SO}_{4}$. Reproduced with permission from Ref. [103]. Copyright 2015, the Royal Society of Chemistry. TEM images of (e) $\mathrm{Co}_{2} \mathrm{P}$ and (f) CoP, with enlarged regions and size distribution in the insets. (g) LSV curves in $0.5 \mathrm{~mol} \mathrm{~L}^{-1} \mathrm{H}_{2} \mathrm{SO}_{4}$ for Co ${ }_{2} \mathrm{P} / \mathrm{Ti}$ and CoP/Ti electrodes, along with Pt mesh and bare Ti foil for comparison. Adapted with permission from Ref. [105]. Copyright 2015, the American Chemical Society. (h) Schematic illustration for the synthesis process of $\mathrm{H}-\mathrm{Co}_{0.85} \mathrm{Se} \mid \mathrm{P}$. (i) TEM and (j) HRTEM images of $\mathrm{H}-\mathrm{Co}_{0.85} \mathrm{Se} \mid \mathrm{P}$. Inset in (i): SAED pattern of $\mathrm{H}-$ $\mathrm{Co}_{0.85} \mathrm{Se} \mid \mathrm{P}$. (k) Simulated scanning TEM image of the $\mathrm{Co}_{0.85} \mathrm{Se}$. (l) Atomic force microscopy (AFM) image of $\mathrm{H}-\mathrm{Co}_{0.85} \mathrm{Se} \mid \mathrm{P}$ on silicon substrate. (m) LSV curves of the samples for HER. (n) DFT-calculated free-energy diagrams of the HER. Adapted with permission from Ref. [115]. Copyright 2017, Wiley-VCH Verlag GmbH \& Co. SEM images of as-synthesized CoPs film (o) and CoPS NWs (p) on graphite, and cobalt hydroxide carbonate hydrate nanoplates ( $\mathrm{CHCH} \mathrm{NPls)} \mathrm{on} \mathrm{carbon} \mathrm{fiber} \mathrm{paper} \mathrm{before}(\mathrm{q})$ and after $(\mathrm{r})$ thermal conversion into CoPS NPls. (s) LSV curves of the samples. ( $\mathrm{t}$ ) Free-energy diagram. Reproduced with permission from Ref. [117]. Copyright 2015, Nature Publishing Group. 
ing the HER activity.

\section{Modulation on d-band centers}

HER falls in the category of heterogeneous catalysis, which occurs on the surface of the catalyst through the key hydrogen adsorption step, and an ideal hydrogen adsorption commonly indicates a good electrocatalytic HER activity. DFT calculations suggest the d-band center could largely describe the adsorbate-metal interaction on catalyst surfaces. The coupling between the valence state of the adsorbate and the d-band of the transition metals greatly reflects the adsorption energy variation of the adsorbate. The higher-energy $\mathrm{d}$ states relative to the Fermi energy (the highest occupied state) of the transition metals indicate the stronger interaction with the adsorbate [102], and vice versa. Chen et al. [119] used transition metal $\mathrm{V}$ doping to tailor the d-band center of $\mathrm{Co}_{4} \mathrm{~N}$ NSs (Fig. 7a), thereby facilitating the $\mathrm{H}$ desorption, and leading to an enhanced HER electrocatalytic activity $\left(37 \mathrm{mV}\right.$ at $10 \mathrm{~mA} \mathrm{~cm}^{-1}$ ) (Fig. 7c), even comparable to Pt/ $\mathrm{C}$ catalysts. Through a series of characterizations, especially Co L-edge X-ray absorption near edge structure (XANES) (Fig. 7b), ultraviolet photoelectron spectroscopy (UPS), and DFT calculations, they suggested that the improved HER electrocatalytic activity is because of the downshift of the d-band center, which weakens the adsorption of hydrogen. The DFT calculations suggest $\mathrm{V}$ doped $\mathrm{Co}_{4} \mathrm{~N}$ shows d-band center which is much farther away from the Fermi level than $\mathrm{Co}_{4} \mathrm{~N}$ (the d-band centers for $\mathrm{Co}_{4} \mathrm{~N}$ and $\mathrm{V}$ doped $\mathrm{Co}_{4} \mathrm{~N}$ relative to the Fermi energy are -1.79 and $-1.85 \mathrm{eV}$, respectively) (Fig. $7 \mathrm{~d}$ ), and more electrons fill the anti-bonding states after $\mathrm{V}$ doping, facilitating the hydrogen desorption, thereby optimizing the $\Delta G_{\mathrm{H}^{*}}$ (Fig. 7e). Pan et al. [120] used a self-template conversion method to synthesize a CoP hollow polyhedron frame (HPF) catalyst doped with foreign metal (Fig. 7f). It is found that the doping of Ni can effectively optimize the electronic structure and d-band center of $\mathrm{CoP}$, and the L-edge absorption of Co shifts negatively after metal doping (Fig. $7 \mathrm{~g}$ ), indicating that the electron transfer from the doped metal to the Co atom makes the electron density around the Co atom higher, which is conducive to the HER progress (Fig. $7 \mathrm{~h}$ ). The $\Delta G_{\mathrm{H}^{*}}$ after $\mathrm{Ni}$ doping is close to $0 \mathrm{eV}$, indicating that it has more suitable hydrogen binding energy (Fig. 7i). Besides, the doping of $\mathrm{Ni}$ makes the d-band center downshift from Fermi level (Fig. 7j), thus reducing the hydrogen adsorption energy, promoting the desorption of $\mathrm{H}$ from the catalysts' surface and improving the HER performance.

\section{Design and engineering on heterointerfaces}

Recently, many researchers are focusing on constructing heterostructures for HER. Rational design and controllable synthesis of heterostructured catalysts with the ideal heterointerfaces can selectively integrate the advantages of different components, overcome the shortcomings of the single components, so as to achieve superior electrocatalytic performances, and the formed heterointerfaces even may give unexpected performances and effects [121]. Most of the reported heterostructured catalysts can be divided into two classes, active/active and active/non-active, both showing enhanced electrocatalytic performances than their counterparts for the following superiorities [122].

(1) Most of the reported heterostructures show welldefined nanostructures, substantially exposing active sites, which can offer more adsorption sites for hydrogen intermediates. Lin et al. [123] recently reported $\mathrm{CoP} /$ $\mathrm{NiCoP}$ nanotadpoles (NTs)-like heterojunction (Fig. 7k and l) for efficient electrocatalytic HER over a wide $\mathrm{pH}$ range (Fig. $7 \mathrm{~m}$ and $\mathrm{n}$ ). Characterizations suggested the $\mathrm{CoP} / \mathrm{NiCoP}$ NTs possess rich heterointerfaces between $\mathrm{CoP}$ and NiCoP, which may expose more active sites for HER. DFT calculations proved that an optimized $\Delta G_{\mathrm{H}^{*}}$ and $\mathrm{H}_{2} \mathrm{O}$ dissociation are achieved at the heterointerface, accelerating the HER reaction in electrolytes with different $\mathrm{pH}$ values.

(2) Introducing bulk (such as carbon cloth/paper, nickel foam, Ti foils) or nanosized (such as CNTs, graphene-based materials or graphitic carbon nitride, 2D transition metal dichalcogenide) substrates to form active/non-active heterostructures is a widely used and readily implementable strategy to construct efficient HER electrocatalysts, which can not only enhance the conductivity and accelerate the mass diffusion in the electrocatalytic process, but also offer a higher specific surface area to disperse the active species, exposing more active sites, meanwhile, avoiding the agglomeration, thus improving both the activity and stability.

(3) The stability of the catalysts can also be improved by the construction of heterostructures. For example, through the formation of the well-defined core@shell structures, the stable species can protect the other active but not stable species. Lin et al. [124] synthesized multidimensional $\mathrm{Ni} / \mathrm{NiCoP}$ nano-heterojunctions (NHs). In this heterojunction structure, Ni NPs are enclosed and then strung by single-phased $\mathrm{NiCoP}$, forming strings of snap bean-like core@shell structures. This particular structure not only takes the most of advantages of $\mathrm{Ni}$ metal and bimetallic phosphides nanostructures, but also 

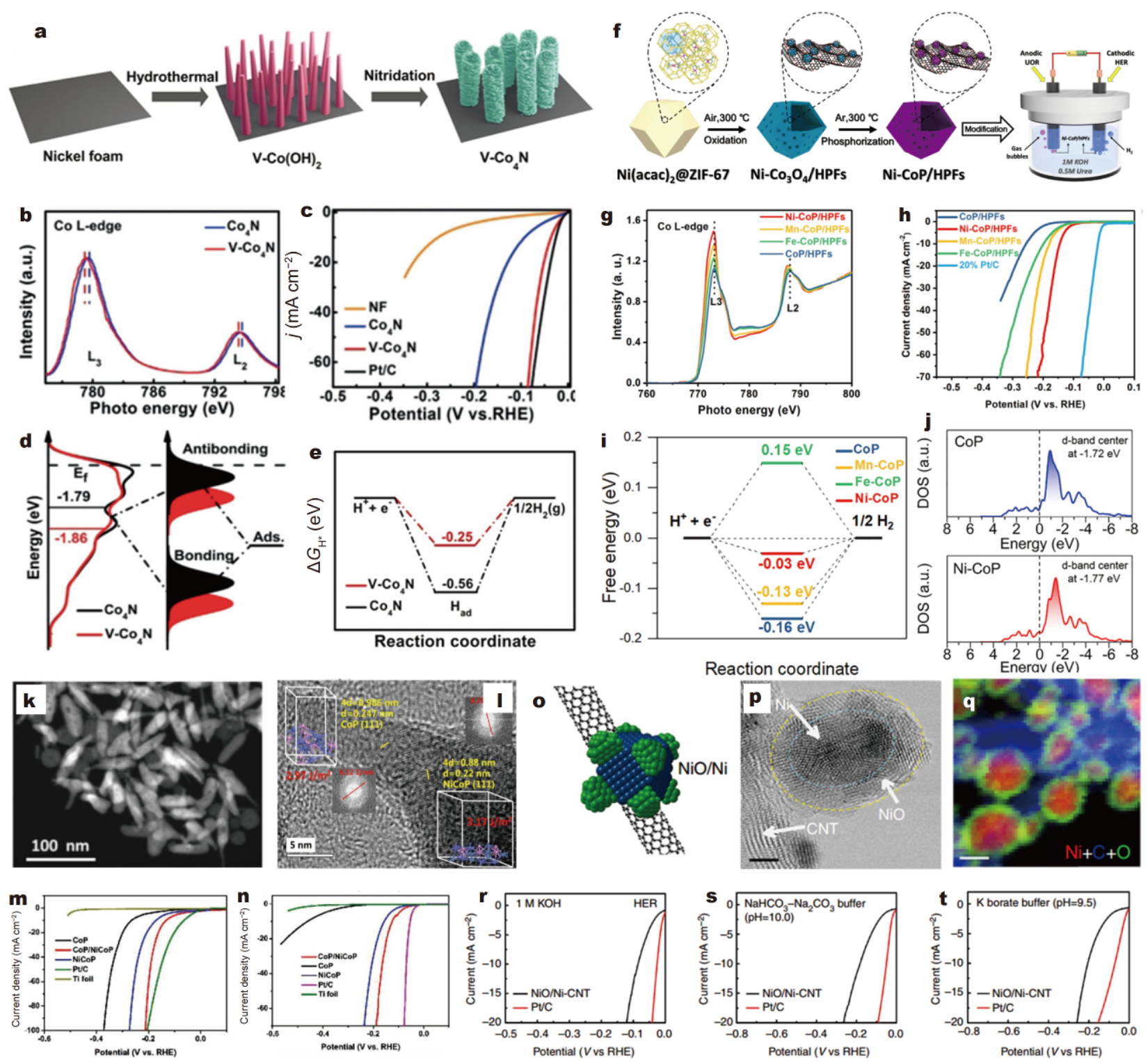

Figure 7 (a) Schematic representation of the preparation of a V-Co ${ }_{4} \mathrm{~N}$ NS. (b) XANES Co L-edge spectra for $\mathrm{Co}_{4} \mathrm{~N}$ and V-Co $\mathrm{Co}_{4} \mathrm{~N}$. The dashed lines highlight the peak positions. (c) LSV of Ni foam, $\mathrm{Co}_{4} \mathrm{~N}, \mathrm{~V}-\mathrm{Co}_{4} \mathrm{~N}$, and Pt/C. (d) The DOS plots of $\mathrm{Co}_{4} \mathrm{~N}$ and V-Co $\mathrm{Co}_{4} \mathrm{~N}$ as well as the corresponding schematic illustration of bond formation between the reaction surface and the adsorbate. The d-band centers are also highlighted in the DOS curves. (e) Free-energy diagram for the HER on $\mathrm{Co}_{4} \mathrm{~N}$ and $\mathrm{V}-\mathrm{Co}_{4} \mathrm{~N}$. Adapted with permission from Ref. [119]. Copyright 2018, Wiley-VCH Verlag GmbH \& Co. (f) Schematic illustration of the Ni-CoP/HPFs. (g) XANES spectra at the Co L-edge of CoP/HPFs and M-CoP/HPFs. (h) LSV curves in 0.5 mol L ${ }^{-1}$ $\mathrm{H}_{2} \mathrm{SO}_{4}$. (i) The calculated free-energy diagram of Ni-CoP, Mn-CoP, Fe-CoP and CoP. (j) Calculated DOS curves for CoP and Ni-CoP. Reprinted with permission from Ref. [120]. Copyright 2019, Elsevier. (k) HAADF-STEM and (l) HRTEM (inset shows the calculated surface energies and FFT images of $\mathrm{CoP}$ and $\mathrm{NiCoP}$ ) of CoP/NiCoP NTs. LSV curves in (m) $1 \mathrm{~mol} \mathrm{~L}^{-1} \mathrm{KOH}$ and (n) $0.5 \mathrm{~mol} \mathrm{~L}^{-1} \mathrm{H}_{2} \mathrm{SO}_{4}$. Adapted with permission from Ref. [123]. Copyright 2019, Wiley-VCH Verlag GmbH \& Co. (o) A schematic illustration of the NiO/Ni-CNT structure. (p) Atomic resolution STEM bright-field image showing the structure of a typical $\mathrm{NiO} / \mathrm{Ni}$ particle on a CNT (small NiO NPs over a larger Ni nanoparticle core). Scale bar, $2 \mathrm{~nm}$. (q) Reconstructed elemental maps with $\mathrm{Ni}$ in red, $\mathrm{C}$ in blue and $\mathrm{O}$ in green for (d) NiO/Ni-CNT, scale bar is $5 \mathrm{~nm}$. (r) LSV curves of NiO/Ni-CNT and $\mathrm{Pt} / \mathrm{C}$ in (s) $1 \mathrm{~mol} \mathrm{~L}{ }^{-1} \mathrm{KOH},(\mathrm{t}) \mathrm{NaHCO}_{3}-\mathrm{Na}_{2} \mathrm{CO}_{3}$ buffer ( $\mathrm{pH}$ 10.0) and (j) potassium borate buffer ( $\mathrm{pH}$ 9.5). Reproduced with permission from Ref. [24]. Copyright 2014, Nature Publishing Group.

avoids the disadvantages ( $\mathrm{Ni}$ is high conductivity, but easy to corrode and unstable in electrolyte; bimetallic phosphides have high activity and stability, but with poor conductivity). Thus, the activity and stability are both 
elevated.

(4) The different components in heterostructures show different electronegativities, and lead to the electronic redistribution between different components, which can tune the electronic structure or the band structures of the electrocatalysts, thereby enhancing the catalytic performance for HER. The electronic redistribution can be well reflected by the XPS, especially the synchrotron-radiation-based X-ray absorption spectroscopy (XAS). Recent studies suggested that the formation of the heterointerfaces in heterostructured $\mathrm{Ni} / \mathrm{NiCoP} \mathrm{NHs}$ and $\mathrm{CoP} /$ $\mathrm{NiCoP}$ NTs can tune the electronic structures of the catalysts, thus promoting the HER process $[123,124]$.

Besides, synergistic effect between different components (which may be reflected indirectly in the above four factors) is also an important factor that, as most of relevant researchers have stated, contributes greatly to the enhancement of HER electrocatalytic performance. Gong et al. [24] constructed nickel oxide/nickel heterostructures on carbon nanotube sidewalls (Fig. 7o-q), which showed a high HER electrocatalytic performance (Fig. $7 \mathrm{r}-\mathrm{t}$ ) even similar to that of $\mathrm{Pt} / \mathrm{C}$ in $1 \mathrm{~mol} \mathrm{~L}^{-1} \mathrm{KOH}$. Based on DFT calculation results, they believed that the formation and desorption of $\mathrm{OH}^{-}$may be a key step in alkaline HER process. On the hetero-interface of the nickel oxide/nickel heterostructures, synergy between $\mathrm{Ni}$ and $\mathrm{NiO}$ is responsible for the excellent HER activity. By virtue of the stronger electrostatic affinity and more unfilled $\mathrm{d}$ orbitals in $\mathrm{Ni}^{2+}$ of $\mathrm{NiO}$ than in $\mathrm{Ni}$ metal, $\mathrm{OH}^{-}$is more inclined to adsorb on the $\mathrm{NiO}$ sites, whereas the nearby $\mathrm{Ni}$ sites benefit the $\mathrm{H}$ adsorption. The synergy between the two components promotes the alkaline HER process. Wang et al. [125] reported 1D metal/sulfide heterostructures $(\mathrm{PtNi} / \mathrm{NiS})$ for acidic and alkaline HER. DFT was used to calculate the energy barrier for $\mathrm{H}_{2} \mathrm{O}$ dissociation (breaking the $\mathrm{OH}-\mathrm{H}$ bond), and the result suggests Pt (111) surface has a much higher energy barrier $(0.89 \mathrm{eV})$ than $\mathrm{NiS}(100)$ surface $(0.32 \mathrm{eV})$, indicating that the NiS surface can promote the step of water dissociation, and then promote the formation of the $\mathrm{H}_{\text {ads }}$. $\mathrm{Pt}_{3} \mathrm{Ni}$ (111) shows a $\Delta G_{\mathrm{H}^{\star}}$ value $(0.09$ or $0.13 \mathrm{eV})$ closer to 0 than that of $\mathrm{NiS}(100)(0.56 \mathrm{eV})$, suggesting that $\mathrm{Pt}_{3} \mathrm{Ni}$ is beneficial for producing $\mathrm{H}_{2}$. In brief, the synergy between $\mathrm{Pt}_{3} \mathrm{Ni}$ and $\mathrm{NiS}$ contributes greatly to the enhanced HER activity in alkaline. NiS shows a stronger electrostatic affinity to adsorb the $\mathrm{OH}^{-}$and avoid blockade of the active sites on Pt by virtue of the unfilled d orbitals on $\mathrm{Ni}^{2+}$, and the produced $\mathrm{H}^{+}$adsorbed on the nearby spare Pt sites for the subsequent $\mathrm{H}_{2}$ formation.

\section{SINGLE-ATOM SITE CATALYSTS ENGINEERING FOR HER}

\author{
Noble-metal-based SASCs
}

\section{Pt SASCs}

Metallic Pt is thus far recognized as the most active HER catalyst. In this regard, currently the main tasks are to further elevate its activity and reduce its loading in the overall catalyst. The emerging concept of "single-atom catalysis" offers a feasible solution to the above issues. Single-atom catalysts (SACs) can be considered as supported catalysts with their catalytic entities downsized to the extreme, and thus can maximize the utilization efficiency of noble metals. Therefore, single-atom Pt are the most frequently reported HER catalysts featuring single atoms of noble metals. Liu et al. [126] designed a SAC with $\mathrm{Pt}$ atoms anchored on onion-like carbon spheres (denoted as $\mathrm{Pt}_{1} / \mathrm{OLC}$ ) (Fig. 8a-d), with a Pt loading as low as $0.27 \mathrm{wt} \%$. In $0.5 \mathrm{~mol} \mathrm{~L}^{-1} \mathrm{H}_{2} \mathrm{SO}_{4}$, the $\mathrm{Pt}_{1} / \mathrm{OLC}$ catalyst gives a low overpotential $\left(38 \mathrm{mV}\right.$ at $\left.10 \mathrm{~mA} \mathrm{~cm}^{-2}\right)$ and a high TOF value $\left(40.78 \mathrm{H}_{2} \mathrm{~s}^{-1}\right.$ at $100 \mathrm{mV}$ ) (Fig. 8e and f). These data are not only superior to those for the $\mathrm{Pt}_{1} /$ graphene catalyst with a similar Pt loading (0.33 wt\%) obtained via the same preparation method, but also comparable to those for commercial $\mathrm{Pt} / \mathrm{C}$ catalyst with a loading of $20 \mathrm{wt} \%$. XANES and EXAFS combined with HRTEM have revealed that, benefiting from the high surface curvature of the OLC support, the single-atom Pt sites have a local electric field effect. This unique structure attracts protons to concentrate at the Pt sites, and promotes the proton coupled electron transfer process, leading to outstanding HER performances. This work presents a new strategy to elevate the activity of singleatom sites by modulating the nanostructure of carbon support. Zhang et al. [127] reported an in situ electrochemical exfoliation method (Fig. 8g) to anchor single $\mathrm{Pt}$ atoms on $\mathrm{Mo}_{2} \mathrm{TC}_{2} \mathrm{~T}_{x}$ support during the HER process. In the obtained catalyst, each $\mathrm{Pt}$ atom occupies a Mo vacancy in the support, and forms three $\mathrm{Pt}-\mathrm{C}$ bonds with adjacent $\mathrm{C}$ atoms (Fig. $8 \mathrm{~h}$ and i). In $0.5 \mathrm{~mol} \mathrm{~L}^{-1} \mathrm{H}_{2} \mathrm{SO}_{4}$, the catalyst gives an overpotential as low as $30 \mathrm{mV}$ at $10 \mathrm{~mA} \mathrm{~cm}^{-2}$. The mass activity is 40 times as high as that for commercial 20\% Pt/C catalyst (Fig. $8 \mathrm{j}$ and k). Also, the catalyst displays an outstanding stability during the electrocatalytic test, with barely any decline in activity after 10,000 cyclic voltammetry cycles or $100 \mathrm{~h}$ chronoamperometry. Ye et al. [128] developed a simple microwave-assisted method to reduce $\mathrm{Pt}$ precursor into single atoms supported on aniline-stacked graphene (Pt 

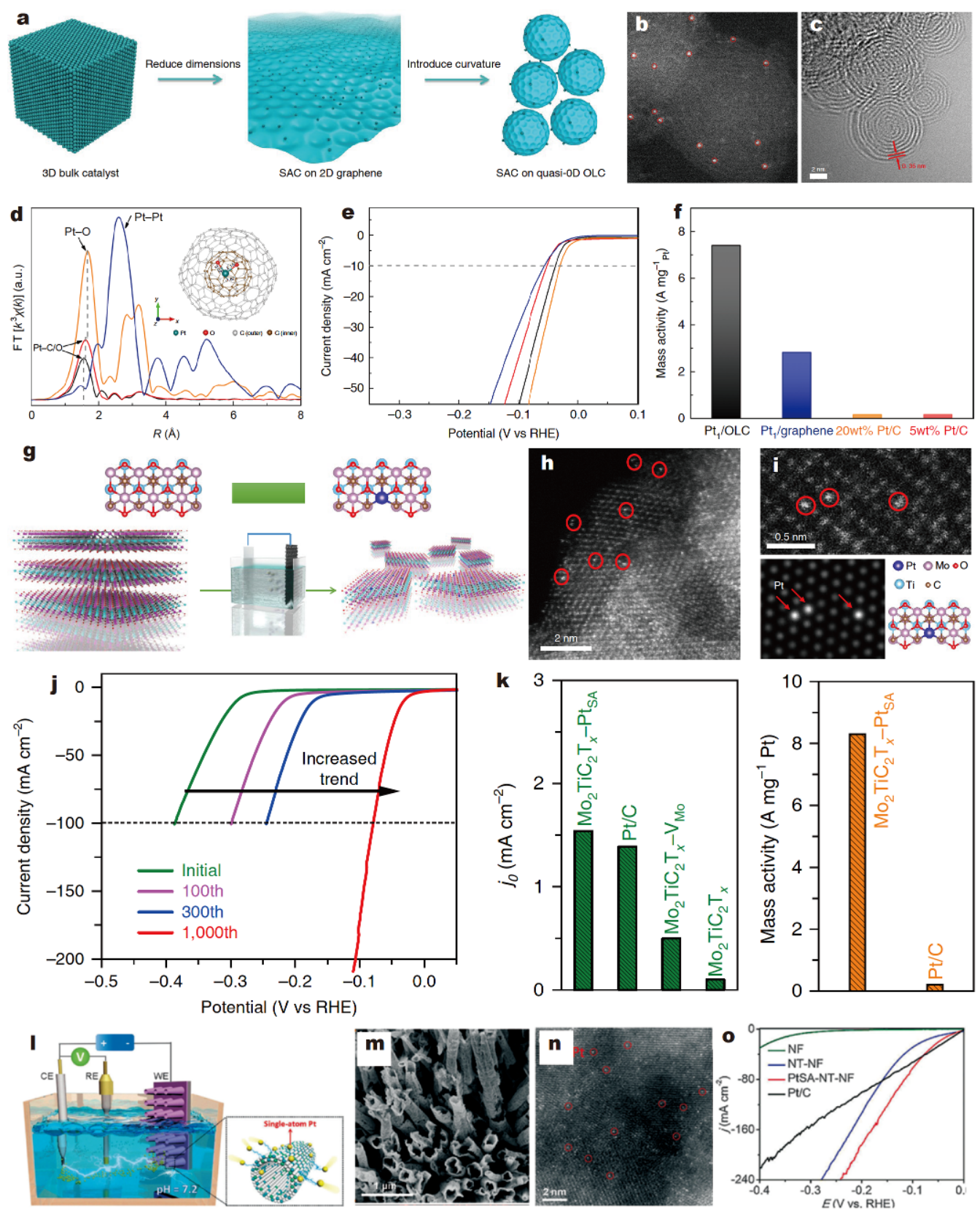

Figure 8 (a) The schematic illustration of $\mathrm{Pt}_{1} / \mathrm{OLC}$. (b) Spherical aberration (AC) corrected HAADF-STEM and (c) HRTEM images of Pt $/$ /OLC. (d) The $\mathrm{Pt}_{3}$ edge FT-EXAFS spectra of $\mathrm{Pt}_{1} / \mathrm{OLC}$ (red), along with $\mathrm{PtO}_{2}$ (yellow), Pt foil (blue) and the Pt ligands/OLC (black) (without $\mathrm{O}_{3}$ exposure to remove their ligands in $\mathrm{MeCpPtMe}_{3}$ precursors) for comparison. Inset: the optimized atomic model of $\mathrm{PtO}_{2} \mathrm{C}_{295}$, which exhibits $\mathrm{Pt}-\mathrm{O}$ bonding in accordance with the experiments, where the grey and brown balls represent the carbon atoms in the outer/inner shell of fullerene-like structure. (e) LSV curves of $\mathrm{Pt}_{1} / \mathrm{OLC}$ (black) in comparison with $5 \mathrm{wt} \%$ and $20 \mathrm{wt} \%$ commercial Pt/C (red and orange, respectively) and $\mathrm{Pt}_{1} / \mathrm{graphene}(0.33 \%)(\mathrm{blue})$ in a $0.5 \mathrm{~mol} \mathrm{~L}^{-1} \mathrm{H}_{2} \mathrm{SO}_{4}$ electrolyte. (f) The mass activity of $\mathrm{Pt}_{1} / \mathrm{OLC}$ is normalized to the Pt loading at an overpotential of $38 \mathrm{mV}$ with respect to the reference catalysts. Reproduced with permission from Ref. [126]. Copyright 2019, Nature Publishing Group. (g) Schematic of the electrochemical exfoliation process of MXene with immobilized single Pt atoms. (h) AC-HAADF-STEM image of $\mathrm{Mo}_{2} \mathrm{TiC}_{2} \mathrm{~T}_{x}-\mathrm{Pt}_{\mathrm{SA}}$. (i) Magnified HAADF-STEM image of $\mathrm{Mo}_{2} \mathrm{TiC}_{2} \mathrm{~T}_{x}-\mathrm{Pt}_{\mathrm{SA}}$ and its corresponding simulated image, and illustration of the structure of $\mathrm{Mo}_{2} \mathrm{TiC}_{2} \mathrm{~T}_{x}-\mathrm{Pt}_{\mathrm{SA}}$, showing the isolated $\mathrm{Pt}$ atoms (circles in (g) and (h)). (j) HER LSV curves of the samples in $0.5 \mathrm{~mol} \mathrm{~L}^{-1} \mathrm{H}_{2} \mathrm{SO}_{4}$ solution. (k) Exchange current densities of the catalysts, and the mass activities of state-of-the-art Pt/C and $\mathrm{Mo}_{2} \mathrm{TiC}_{2} \mathrm{~T}_{x}$-PtSA. Reproduced with permission from Ref. [127]. Copyright 2018, Nature Publishing Group. (l) Schematic diagram of the synthesis process. CE: counter electrode; RE: reference electrode; WE: working electrode. The CE is Pt. (m) SEM image of a piece of $\mathrm{Pt}_{\mathrm{SA}}-\mathrm{NT}-\mathrm{NF}$. (n) AC-HAADF-STEM of $\mathrm{Pt}_{\mathrm{SA}}-\mathrm{NT}$-NF. (o) HER polarization curves of NF, NT-NF, $\mathrm{Pt}_{\mathrm{SA}}-\mathrm{NT}-\mathrm{NF}$, and Pt/C in N $\mathrm{N}_{2}$-saturated $1.0 \mathrm{~mol} \mathrm{~L}^{-1}$ PBS. Adapted with permission from Ref. [130]. Copyright 2017, Wiley-VCH Verlag GmbH \& Co. 
SASs/AG, with a Pt loading of merely $0.44 \%$ ). The catalyst gives an excellent HER activity (an overpotential of $12 \mathrm{mV}$ at $10 \mathrm{~mA} \mathrm{~cm}^{-2}$; at an overpotential of $50 \mathrm{mV}$, the mass activity reaches up to $22,400 \mathrm{Ag}(\mathrm{Pt})^{-1}, 46$ times as high as that for commercial $20 \mathrm{wt} \% \mathrm{Pt} / \mathrm{C}$ ). Zhang et al. [129] reported a novel dynamic reaction approach to relocate the single Pt atoms on the surface of the precursor (carbon spheres) into the interiors of the porous carbon matrix (PCM). HER tests reveal that the Pt atoms immobilized in the crystal lattice of PCM display outstanding performances in both acid and alkali.

Pt-based SACs can also give high HER performance under neutral conditions. Zhang et al. [130] found that during the electrocatalytic reaction (Fig. 81), the Pt atoms on Pt anode can be dissolved into the electrolyte and then deposited on the cathode; by exploiting this process, they developed a novel potential-cycling method, and prepared Pt atoms on CoP-based nanotube (NT) arrays supported by a Ni foam (NF) (denoted as PtSA-NT-NF) (Fig. $8 \mathrm{~m}-\mathrm{n}$ ). For HER in neutral electrolyte (pH 7.2), the catalyst gives an overpotential of $24 \mathrm{mV}$ at $10 \mathrm{~mA} \mathrm{~cm}^{-2}$ (Fig. 8o); at an overpotential of $50 \mathrm{mV}$, the mass activity reaches $70 \mathrm{~A} \mathrm{~g}^{-1}$, which is four times of that for commercial $20 \mathrm{wt} \% \mathrm{Pt} / \mathrm{C}$. Also, the catalyst displays a low Tafel slope $\left(30 \mathrm{mV} \mathrm{dec}^{-1}\right)$ and a high stability. This method is also proved to be a general preparation method for Pt-based SACs, with a range of materials applicable as the cathode. Jiang et al. [131] employed a similar route and prepared a catalyst comprising single Pt atoms supported on nanosized porous cobalt selenide (Pt/np$\mathrm{Co}_{0.85} \mathrm{Se}$ ). In neutral electrolyte ( $\mathrm{pH} 7$ ), the catalyst also displays an HER electrocatalytic performance superior to those of commercial Pt/C. By operando XAS and DFT calculations, the team identified that the high HER activity originates from the synergy between single $\mathrm{Pt}$ atoms and $\mathrm{np}-\mathrm{Co}_{0.85} \mathrm{Se}$.

\section{Ru SASCs}

Besides Pt, single atoms of other noble metals (such as $\mathrm{Ru}$ ) have also been reported as catalysts for HER. Yang et al. [132] employed phosphorus nitride (PN) nanotubes as support, and thereupon anchored single $\mathrm{Ru}$ atoms via the interaction between the $\mathrm{d}$ orbitals of $\mathrm{Ru}$ and the lone-pair electrons of $\mathrm{N}$. The resulting catalyst displays a high HER activity in acid, with an overpotential of $24 \mathrm{mV}$ at $10 \mathrm{~mA} \mathrm{~cm}^{-2}$, a Tafel slope of $38 \mathrm{mV} \mathrm{dec}^{-1}$. The TOF reaches 1.67 and $4.29 \mathrm{H}_{2} \mathrm{~s}^{-1}$ at 25 and $50 \mathrm{mV}$, respectively. The catalyst also exhibits a good stability at a current density as large as $160 \mathrm{~mA} \mathrm{~cm}{ }^{-2}$. Ramalingam et al. [133] used 2D titanium carbide $\left(\mathrm{Ti}_{3} \mathrm{C}_{2} \mathrm{~T}_{x}\right)$ MXene as an effective carrier to load $\mathrm{Ru}$ single atoms (RuSA-N-S$\mathrm{Ti}_{3} \mathrm{C}_{2} \mathrm{~T}_{x}$ ) (Fig. 9a-d). Through the formation of the Ru$\mathrm{N}, \mathrm{Ru}-\mathrm{S}$ bonds to stabilize Ru single atom (Fig. 9e). And the synthesized RuSA-N-S- $\mathrm{Ti}_{3} \mathrm{C}_{2} \mathrm{~T}_{x}$ shows outstanding HER electrocatalytic performance in acid, which only needs $76 \mathrm{mV}$ to reach $10 \mathrm{~mA} \mathrm{~cm}^{-2}$ (Fig. 9f). Theoretical calculation suggests the activity enhancement derives from the coordination effect of $\mathrm{N}$ and $\mathrm{S}$ in $\mathrm{Ru}$ and $\mathrm{Ti}_{3} \mathrm{C}_{2} \mathrm{~T}_{x}$ MXene (Fig. 9g and h). Therefore, Ru-based SACs for HER can also display superior activity and stability to those of commercial $\mathrm{Pt} / \mathrm{C}$. Considering that $\mathrm{Ru}$ is far less expensive than $\mathrm{Pt}$, these Ru-based SACs are expected to play a major role in future large-scale HERrelated applications. Besides the SACs based on noble metals, Zhang et al. [134] also prepared bimetallic dimer structures (Pt-Ru dimers) for acidic HER, showing higher HER activity ( $>50$ times higher than that of the commercial $\mathrm{Pt} / \mathrm{C}$ ) and excellent stability due to the synergy effect.

\section{Ir SASCs}

Lai et al. [135] used the $\pi$ electrons on imidazole group of ZIF-67 to bond metal ions $\mathrm{M}(\mathrm{M}=\mathrm{Ir}, \mathrm{Pt}, \mathrm{Ru}, \mathrm{Pd}, \mathrm{Fe}, \mathrm{Ni})$ to form single-atom sites on a heterogeneous support composed by the nitrogen-doped carbon matrix (N/C) and Co NPs. The single-atoms can simultaneously anchor on these two distinct domains, forming M@NC, and centers of M@Co. The single-atom Ir catalyst exhibits the best electrocatalytic performance. DFT calculations indicate that the Ir@Co sites benefit the OER, while the Ir@NC $\mathrm{N}_{3}$ sites promote the HER process, accelerating the full water splitting.

\section{None-noble-metal-based SASCs}

\section{Ni SASCS}

Zhang et al. [136] reported a catalyst featuring single $\mathrm{Ni}$ atoms anchored on defective graphene (A-Ni@DG), which displays a high activity for electrochemical water splitting. For OER in acid $\left(0.5 \mathrm{~mol} \mathrm{~L}^{-1} \mathrm{H}_{2} \mathrm{SO}_{4}\right)$ and alkali $\left(1 \mathrm{~mol} \mathrm{~L}^{-1}\right.$ $\mathrm{KOH})$, the catalyst displays an overpotential of 70 and $270 \mathrm{mV}$ at $10 \mathrm{~mA} \mathrm{~cm}^{-2}$, respectively, far superior to commercial Ir/C catalyst, and the HER activity is close to that of commercial $\mathrm{Pt} / \mathrm{C}$ as well. Li et al. [137] reported a singleatom tailoring strategy to prepare $\mathrm{Pt}$ nanowires decorated with single Ni atoms (denoted as SANi-PtNWs) (Fig. 9i-l). Most activated Pt sites were created with adjacent nickel atoms, which endow the catalyst with a high HER activity in alkaline media. At an overpotential of $-70 \mathrm{mV}$, the mass activity reaches $11.8 \pm 0.43 \mathrm{~A} \mathrm{mg}(\mathrm{Pt})^{-1}$, far surpassing the 

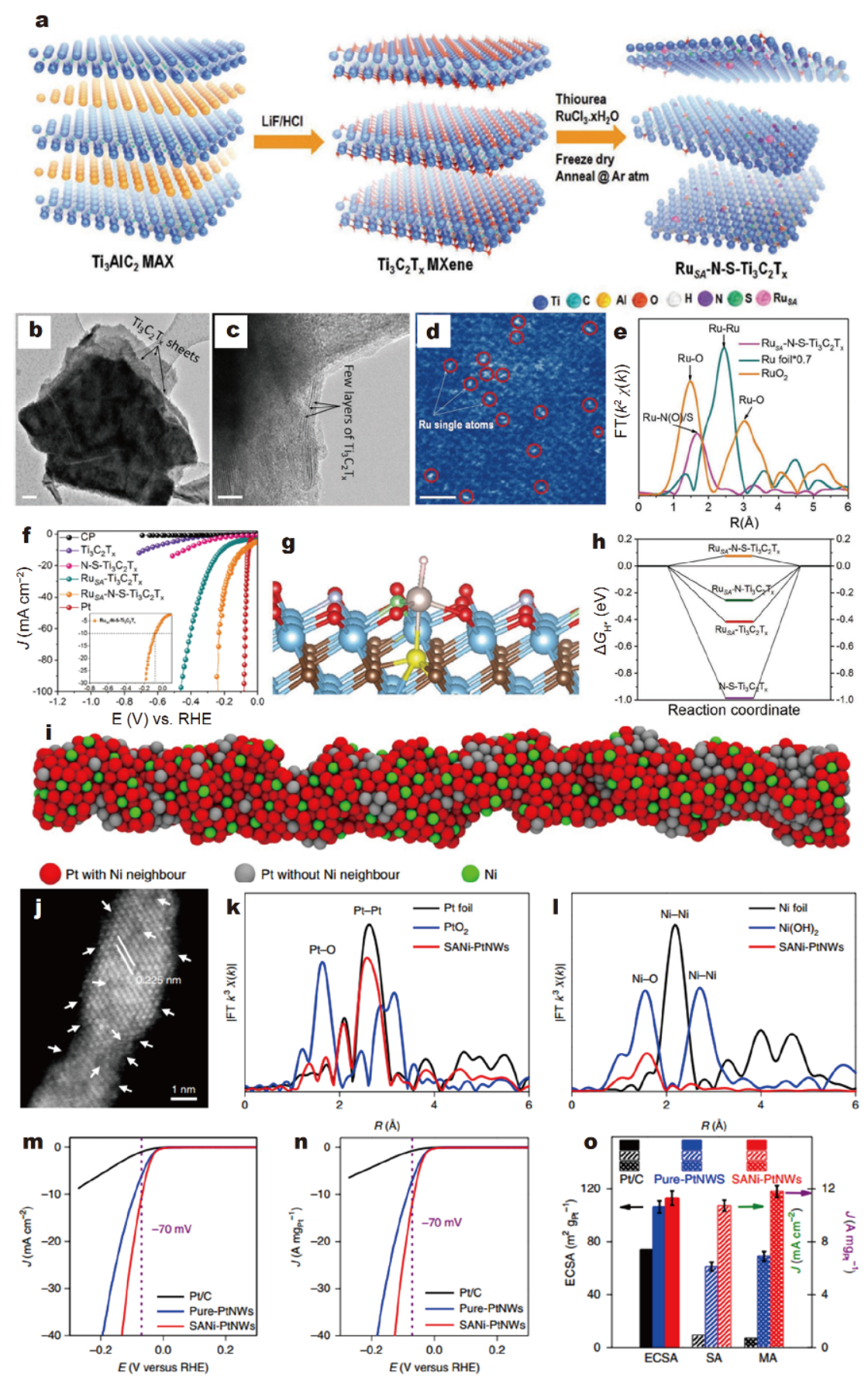

Figure 9 (a) Schematic illustration of the synthesis route of RuSA-N-S-Ti ${ }_{3} \mathrm{C}_{2} \mathrm{~T}_{x}$ catalyst. (b) TEM image of RuSA-N-S-Ti ${ }_{3} \mathrm{C}_{2} \mathrm{~T}_{x}$ shows the $2 \mathrm{D}$ Ti ${ }_{3} \mathrm{C}_{2} \mathrm{~T}_{x}$ NSs. Scale bar, $200 \mathrm{~nm}$. (c) HRTEM image of few-layered RuSA-N-S-Ti ${ }_{3} \mathrm{C}_{2} \mathrm{~T}_{x}$, scale bar, $20 \mathrm{~nm}$. (d) AC-HAADF-STEM image of RuSA-N-S-Ti ${ }_{3} \mathrm{C}_{2} \mathrm{~T}_{x}$ (bright dots marked with red circles indicate the $\mathrm{Ru}_{\mathrm{SA}}$ on the $\mathrm{Ti}_{3} \mathrm{C}_{2} \mathrm{~T}_{x}$ MXene support). Scale bar, $2 \mathrm{~nm}$. (e) The FT-EXAFS spectra. (f) HER LSV curves of the catalysts in $0.5 \mathrm{~mol} \mathrm{~L}^{-1} \mathrm{H}_{2} \mathrm{SO}_{4}$. Inset: the magnified view of the HER polarization curve of $\mathrm{Ru}_{\mathrm{SA}}-\mathrm{N}-\mathrm{S}-\mathrm{Ti}_{3} \mathrm{C}_{2} \mathrm{~T}_{x}$. (g) Atomic model of the $\mathrm{Ru}_{\mathrm{SA}}-\mathrm{N}-\mathrm{S}-\mathrm{Ti}_{3} \mathrm{C}_{2} \mathrm{~T}_{x}$ catalyst (blue, brown, red, light blue, yellow, green, and gray colored balls represent Ti, C, O, F, S, N, and Ru atoms, respectively). (h) The calculated $\Delta G_{\mathrm{H}^{*}}$ diagram. Adapted with permission from Ref. [133]. Copyright 2019, Wiley-VCH Verlag GmbH \& Co. (i) Schematic diagram and (j) HAADF-STEM image of SANi-PtNWs. White arrows highlight the surface defects, steps and concave cavity sites. (k) Pt EXAFS fitting result. (l) Ni EXAFS fitting result. ECSA normalized $(\mathrm{m})$ and Pt mass loading normalized (n) HER LSV curves. (o) Comparison of ECSA (black arrow, left axis), SA values (normalized by ECSA, green arrow, right axis) and MAs (normalized by Pt mass, purple arrow, right axis) for HER at $-70 \mathrm{mV}$ versus RHE for all tested materials. Reproduced with permission from Ref. [137]. Copyright 2019, Nature Publishing Group. 
team's previous record $\left(3.03 \mathrm{~A} \mathrm{mg}(\mathrm{Pt})^{-1}\right.$ for excavated $\mathrm{PtNi}$ nanomultipods) and the then-world-record (7.23 A mg(Pt) ${ }^{-1}$ for PtNi-O octahedra) (Fig. 9m-o). Lou's group [138] reported the partial replacement of Mo atoms in $\mathrm{MoS}_{2}$ by single Ni atoms via surface modification, which could effectively optimize the electronic structures of activated $\mathrm{S}$ atoms in the basal plane, unleashing their inherent activity. To sum up, the introduction of single $\mathrm{Ni}$ atoms is a general and effective approach to preparing high-performance HER catalysts. Besides, on the basis of first principle calculations, Ling et al. [139] designed the first "single-atom bifunctional" catalyst for electrochemical water splitting. The catalyst features single $\mathrm{Ni}$ atoms anchored in $\beta_{12}$ boron monolayer with unique geometry, and is expected to show competence for overall water splitting.

\section{Fe SASCs}

Xue et al. [140] employed graphdiyne as support, and thereupon loaded $\mathrm{Fe}(0)$ and $\mathrm{Ni}(0)$ atoms with atomic dispersion, by taking advantage of the $\mathrm{C} \equiv \mathrm{C}$ bonds, large surface area and high porosity of graphdiyne (GD) (Fig. 10a-d). The resulting Fe(0)/GD and $\mathrm{Ni}(0) / \mathrm{GD}$ catalysts show high activity and stability in HER test, with overpotentials of 66 and $88 \mathrm{mV}$ at $10 \mathrm{~mA} \mathrm{~cm}^{-2}$ (Fig. 10e), respectively. At an overpotential of $0.2 \mathrm{~V}$, the mass activities of these two catalysts are 34.6 and 7.19 times as high as that for commercial 20\% Pt/C (Fig. 10f), with the upper limit number of the active sites of $2.56 \times 10^{16}$ sites per $\mathrm{cm}^{2}$ and $2.38 \times 10^{16}$ sites per $\mathrm{cm}^{2}, 17$ and 15.8 times as high as that for $\operatorname{Pt}(111)\left(1.5 \times 10^{15}\right.$ sites per $\left.\mathrm{cm}^{2}\right)$. This work offers a new strategy for the development and application of zero-valence single-atom metals. Pan et al. [141] reported a polymerization-pyrolysis-evaporation approach and prepared a catalyst with single $\mathrm{Fe}$ atoms anchored on $\mathrm{N}$-doped porous carbon. AC-HAADFSTEM, EXAFS and ${ }^{57} \mathrm{Fe}$ Mossbauer spectroscopy confirmed the active sites with a Fe- $\mathrm{N}_{4}$ structure. The catalyst displays a good HER electrocatalytic performance in alkaline electrolyte $\left(1 \mathrm{~mol} \mathrm{~L}^{-1} \mathrm{KOH}\right)$.

\section{Co SASCs}

Fei et al. [142] published the first report of anchoring single Co atoms on N-doped graphene. By AC-HAADFSTEM and EXAFS, they revealed that the bonding between $\mathrm{Co}$ and $\mathrm{N}$ can promote the HER process. This catalyst displays high activity and stability in both acid $\left(0.5 \mathrm{~mol} \mathrm{~L}^{-1} \mathrm{H}_{2} \mathrm{SO}_{4}\right)$ and alkali $\left(1 \mathrm{~mol} \mathrm{~L}^{-1} \mathrm{KOH}\right)$, with an overpotential of 147 and $270 \mathrm{mV}$ at $10 \mathrm{~mA} \mathrm{~cm}^{-2}$, respectively. This team [143] also reported the fast, mi- crowave-assisted preparation (within $2 \mathrm{~s}$ ) of $\mathrm{N}$-doped graphene supporting different single metal atoms $(\mathrm{Co}, \mathrm{Ni}$, $\mathrm{Cu}$ ). Compared with those obtained via conventional thermolysis, the catalysts obtained with this microwaveassisted method feature less ordered coordination environments around the single metal atoms, and a higher degree of defects. The corresponding Co-based catalyst displays an exceptional HER catalytic performance, with an onset potential close to 0 , a Tafel slope of $80 \mathrm{mV} \mathrm{dec}^{-1}$. At a current density of $10 \mathrm{~mA} \mathrm{~cm}{ }^{-2}$, the overpotential is only $175 \mathrm{mV}$. Sun et al. [144] employed a dual-template cooperative pyrolysis approach (Fig. 10g) and prepared a catalyst comprising highly dispersed Co single-atom-site (SAS) embedded on hierarchically ordered porous $\mathrm{N}$ doped carbon (HOPNC) (denoted as Co-SAS/HOPNC) (Fig. 10h-1). The Co- $\mathrm{N}_{4}$ active sites can effectively alter the electronic structure of the catalyst, and confer a high HER performance in acidic media (Fig. 10m), with an overpotential of $137 \mathrm{mV}$ at $10 \mathrm{~mA} \mathrm{~cm}^{-2}$. At overpotentials of 100 and $200 \mathrm{mV}$, the TOF reaches 0.41 and $3.8 \mathrm{~s}^{-1}$, respectively. The catalyst also displays a good stability.

\section{Mo SASCs}

Chen et al. [145] reported a catalyst with single Mo atoms loaded on $\mathrm{N}$-doped carbon, with $\mathrm{Mo}_{1} \mathrm{~N}_{1} \mathrm{C}_{2}$ active sites. For HER in alkaline electrolyte $\left(0.1 \mathrm{~mol} \mathrm{~L}^{-1} \mathrm{KOH}\right)$, this catalyst displays a higher activity than $\mathrm{Mo}_{2} \mathrm{C}$ and $\mathrm{MoN}$, with an onset potential of merely $13 \mathrm{mV}$. At a current density of $10 \mathrm{~mA} \mathrm{~cm}^{-2}$, the overpotential is only $132 \mathrm{mV}$. Also, the catalyst has a higher stability than $\mathrm{Pt} / \mathrm{C}$. Compared with $\mathrm{Mo}_{2} \mathrm{C}, \mathrm{MoN}$ and $\mathrm{N}$-doped graphene, the $\mathrm{Mo}_{1} \mathrm{~N}_{1} \mathrm{C}_{2}$ catalytic site also showed the lowest absolute value of $\Delta G_{\mathrm{H}^{*}}$, as demonstrated by DFT results.

\section{W SASCS}

Chen et al. [146] designed and prepared a metal-organic frameworks (MOF)-derived catalyst with $\mathrm{N}$-doped carbon supporting single $\mathrm{W}$ atoms (denoted as $\mathrm{W}$-SAC). AC-HAADF-STEM and EXAFS confirmed that the active sites exist in the form of $\mathrm{W}_{1} \mathrm{~N}_{1} \mathrm{C}_{3}$. The catalyst gives a high activity and stability for HER in both acidic and alkaline conditions. In $0.1 \mathrm{~mol} \mathrm{~L}^{-1} \mathrm{KOH}$, the overpotential is $85 \mathrm{mV}$ at $10 \mathrm{~mA} \mathrm{~cm}^{-2}$, only $5 \mathrm{mV}$ higher than that for commercial $\mathrm{Pt} / \mathrm{C}$; the Tafel slope is $53 \mathrm{mV} \mathrm{dec}^{-1}$. In $0.5 \mathrm{~mol} \mathrm{~L}^{-1} \mathrm{H}_{2} \mathrm{SO}_{4}$, the overpotential is $105 \mathrm{mV}$ at $10 \mathrm{~mA} \mathrm{~cm}^{-2}$, and the Tafel slope is $58 \mathrm{mV} \mathrm{dec}^{-1}$. DFT calculation suggested the $\mathrm{W}_{1} \mathrm{~N}_{1} \mathrm{C}_{3}$ moiety played an important role in optimizing hydrogen adsorption free energy, thereby enhancing the HER performance. 

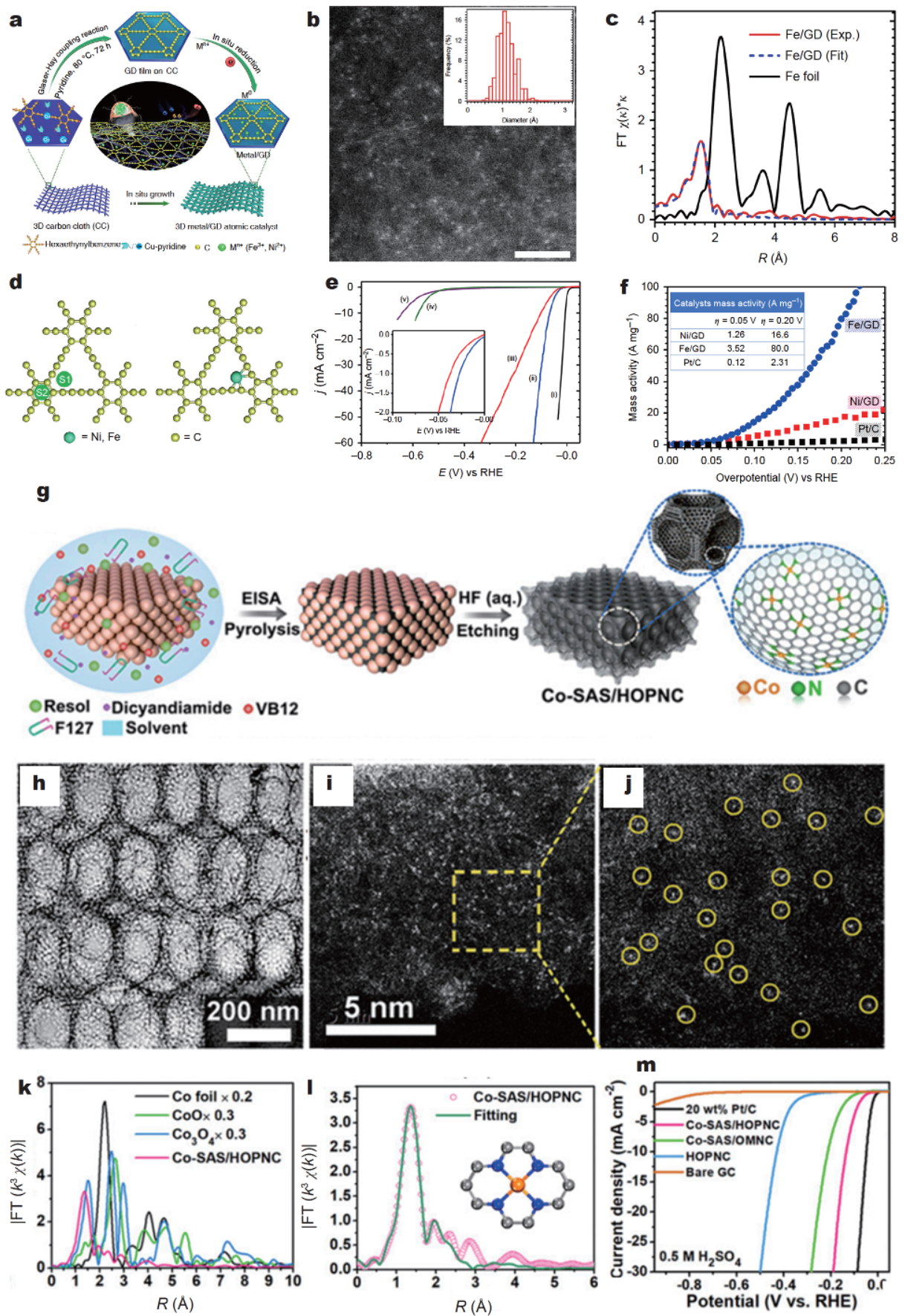

Figure 10 (a) Synthesis protocols for Ni/GD and Fe/GD. (b) AC-HAADF-STEM image of Fe/GD (inset: size distribution of Fe atoms counted from AC-HAADF-STEM images, (>1070 Fe atoms considered, the most probable value is $1.02 \pm 0.33 \AA$ )). Scale bar, $2 \mathrm{~nm}$. (c) Ex situ EXAFS spectra of Fe/ GD and Fe foil at the Fe K-edge. (d) Adsorption of single metal atoms on GD (left: possible adsorption sites; right: optimized configuration). (e) LSV curves of (i) Pt/C, (ii) Fe/GD, (iii) Ni/GD, (iv) GDF, and (v) CC (inset: enlarged view of the LSV curves for Fe/GD and Ni/GD near the onset region). (f) Mass activities of Ni/GD, Fe/GD, and Pt/C (inset: mass activities obtained at overpotentials of 0.05 and $0.20 \mathrm{~V}$ ). Reproduced with permission from Ref. [140]. Copyright 2018, Nature Publishing Group. (g) Schematic illustration of the synthesis of Co-SAS/HOPNC. (h) TEM and (i, j) AC HAADFSTEM images of the Co-SAS/HOPNC. Isolated single Co atoms are marked with light-yellow circles. (k) Fourier transforms of EXAFS curves of CoSAS/HOPNC, $\mathrm{CoO}, \mathrm{Co}_{3} \mathrm{O}_{4}$, and Co foil at Co K edge. (l) The corresponding EXAFS fitting curves of Co-SAS/HOPNC. Inset: schematic model of CoSAS/HOPNC: Co (orange), N (blue), and C (gray). (m) HER LSV curves of the samples. Reproduced with permission from Ref. [144]. Copyright 2018, National Academy of Sciences. 


\section{SASCs}

Zhao et al. [147] prepared a Ni-I precursor in a vacuumsealed ampoule; the sample underwent pyrolysis in vacuum, and cyclic voltammetric activation in $\mathrm{KOH}$ solutions, yielding a single-atom Ni-I catalyst (denoted as SANI-I). Most I atoms in the Ni-I precursor were replaced by oxygen atoms and hydroxide anions during the activation process. By HAADF-STEM and XAS characterizations, atomically dispersed I atoms were confirmed in the single-atom nickel iodide (SANi-I) catalyst. The SANi-I features a high structural stability, and high HER activity. The catalyst can deliver a current density of $100 \mathrm{~mA} \mathrm{~cm}^{-2}$ under an overpotential of $60 \mathrm{mV}$, better than those for $\mathrm{Pt} / \mathrm{C}(61 \mathrm{mV})$ and A-Ni-OH $(285 \mathrm{mV})$. The team investigated the HER mechanism using in situ Raman spectroscopy, and found that the $\mathrm{Ni}$ atoms adjacent to single I atoms can promote the formation of I$\mathrm{H}_{\text {ads }}$ intermediates and thus accelerate the dissociation of adsorbed water molecules. This report uncovers new opportunities for non-metal-based SASCs in the field of energy conversion.

\section{STRUCTURE-ACTIVITY RELATIONSHIP OF SASCS IN HER}

\section{Size effect}

The size of catalyst is one of the key factors that influence the activity. By downsizing the catalytic entities, the atom utilization efficiency can be effectively elevated. For instance, Cheng et al. [148] employed N-doped graphene as support, and thereupon loaded a series of Pt catalysts with varying sizes via atomic layer deposition (ALD). By precisely controlling the ALD cycles, the size of Pt species can vary from single atoms, sub-nanometer clusters, to nanosized particles (Fig. 11a-b). The single Pt atoms and Pt clusters display exceptionally high activities (with a mass activity 37 times as high as that for commercial $20 \%$ $\mathrm{Pt} / \mathrm{C}$ ) and stabilities in $0.5 \mathrm{~mol} \mathrm{~L}^{-1} \mathrm{H}_{2} \mathrm{SO}_{4}$ (Fig. 11c).

\section{Coordination effect}

The in-depth understanding of the structure-activity relationship between the coordination environments in SACs and their catalytic performances would be of guidance for the development and application of new, advanced SACs. For instance, Yin et al. [149] judiciously exploited the coordination affinity between $\mathrm{C} \equiv \mathrm{C}$ bonds in graphdiyne support and $\mathrm{Pt}$ atoms, and successfully constructed two Pt-based SACs that feature different coordination environments (Fig. 11d and e). They found that the four-coordinated $\mathrm{C}_{2}-\mathrm{Pt}-\mathrm{Cl}_{2}$ site has more unoccupied $5 \mathrm{~d}$ orbitals, which is beneficial to the HER process. The catalyst with four-coordinated sites displays a superior HER mass activity and stability in $0.5 \mathrm{~mol} \mathrm{~L}^{-1}$ $\mathrm{H}_{2} \mathrm{SO}_{4}$, with its mass activity 3.3 and 26.9 times as high as
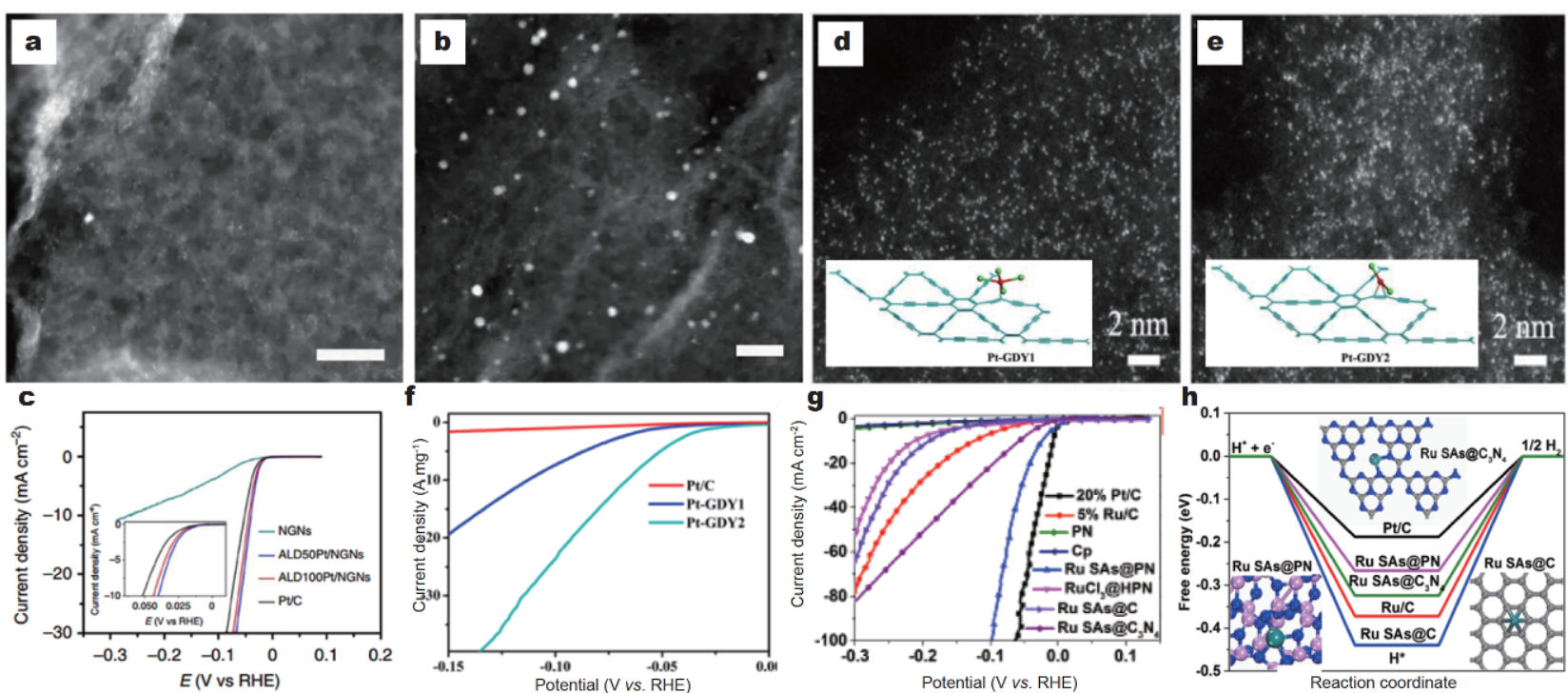

Figure 11 HAADF-STEM images of Pt/NGNs samples with (a) 50 and (b) 100 ALD cycles. Scale bars, $10 \mathrm{~nm}$. (c) The HER LSV curves for Pt/NGNs and $\mathrm{Pt} / \mathrm{C}$ catalysts in $0.5 \mathrm{~mol} \mathrm{~L}^{-1} \mathrm{H}_{2} \mathrm{SO}_{4}$. The inset shows the enlarged curves at the onset potential region of the HER for the different catalysts. Reproduced with permission from Ref. [148]. Copyright 2016, Nature Publishing Group. AC-HAADF-STEM images for Pt-GDY1 (d) and Pt-GDY2 (e). Insets show the corresponding configuration. (f) The LSV curves for Pt-GDY1, Pt-GDY2 and Pt/C in $0.5 \mathrm{~mol} \mathrm{~L}^{-1} \mathrm{H}_{2} \mathrm{SO}_{4}$. Adapted with permission from Ref. [149]. Copyright 2018, Wiley-VCH Verlag GmbH \& Co. (g) The HER LSV curves of the catalysts. (h) The calculated free energy diagram for HER. Adapted with permission from Ref. [132]. Copyright 2018, Wiley-VCH Verlag GmbH \& Co. 
those for the catalyst with five-coordinated C-Pt- $\mathrm{Cl}_{4}$ sites (Fig. 11f) and commercial Pt/C, respectively.

\section{Support effect}

As is well known, the role of support in catalysis is not merely to provide a large specific surface area, but more importantly, to help optimize the local geometric/electronic structures of metal species. For SACs, the support effect becomes more prominent. For instance, Yang et al. [132] compared single Ru atoms anchored on different supports, including PN imide nanotubes, commercial XC-72 conductive carbon black and $\mathrm{C}_{3} \mathrm{~N}_{4}$. They found that the single $\mathrm{Ru}$ atoms on $\mathrm{PN}$ nanotubes give an overpotential as low as $24 \mathrm{mV}$ at $10 \mathrm{~mA} \mathrm{~cm}^{-2}$, only $14 \mathrm{mV}$ higher than that for commercial Pt/C. By contrast, the $\mathrm{Ru}$ atoms anchored on $\mathrm{XC}-72$ and $\mathrm{C}_{3} \mathrm{~N}_{4}$ show 191 and $58 \mathrm{mV}$, respectively (Fig. $11 \mathrm{~g}$ ). The catalyst with PN support has a faster kinetics, with a Tafel slope of $38 \mathrm{mV} \mathrm{dec}^{-1}$, lower than those for XC-72 $\left(122 \mathrm{mV} \mathrm{dec}^{-1}\right)$ and $\mathrm{C}_{3} \mathrm{~N}_{4}\left(125 \mathrm{mV} \mathrm{dec}^{-1}\right)$. Compared with carbon and $\mathrm{C}_{3} \mathrm{~N}_{4}$ support, the $\Delta G_{\mathrm{H}^{*}}$ of the Ru SAs on PN is much closer to 0 , thus improving the HER performance (Fig. 11h). These results confirm that support effect plays a major role in Ru-based SACs for HER.

\section{THE DEVELOPMENT TRENDS AND FACED CHALLENGES OF CATALYSTS FOR ELECTROCHEMICAL HER}

Considering the research processes thus far, SASCs generally display high economicalness by virtue of the uniform active sites and maximized atomic utilization efficiency. Currently, the research on SASCs catering to HER is still in its infancy. Noble-metal-based SASCs have demonstrated activities and stabilities superior to those for commercial $\mathrm{Pt} / \mathrm{C}$, and also feature lower metal loadings and much reduced expenses. Despite the great promises of SACs, the bottlenecks in preparation are still limiting their applications. A major goal in this regard is to achieve the mass production of SASCs based on noble metals. For HER catalysts based on non-noble metals, their activities now can be comparable to that for commercial Pt/C; one of the future tasks is to develop general preparation methods that allow for large-scale production with high loadings, so as to achieve the replacement of noble metals.

For hydrogen production via electrochemical water splitting, it should be firstly noted that, although the reaction can be run at all $\mathrm{pH}$ values, the neutral $\mathrm{pH}$ condition is generally preferred. Second, most of the currently available techniques require pure water as re- actant, whereas resources from other waterbodies (such as sea water, and industrial wastewater) received much less attention, primarily because the impurities in these waters can lead to side reactions and corrosion of the electrodes. Third, electrochemical water splitting, from the perspectives of both fundamental and application, has to overcome the issues of activity and stability under high current densities typical in industry, and relevant tests need to be run at a current density at least 500 or $1000 \mathrm{~mA} \mathrm{~cm}^{-2}$ for long terms. Last but not least, the electrochemical device for water splitting can be coupled with other systems, allowing for rich opportunities in, for example, sunlight-powered water splitting, coordinated HER and chlorine evolution reaction for chloralkali process, coordinated production of hydrogen and sulfur. Therefore, developing SACs with high activity, high selectivity, high stability and low cost for HER is the key to further elevating the catalytic efficiency.

\section{SUMMARY AND PROSPECTS}

In this review, we systematically summarized the research progresses regarding HER-oriented nanocatalysts, discussed the structure-activity relationship, and interpreted their high activities from an atomistic perspective; we also overviewed the design, preparation and applications of a variety of HER-oriented SASCs, as well as the structureactivity relationship at the atomic level, and discussed the future directions for the development of high-performance SASCs for HER. At the current stage, the research on SASCs is still at its infancy, and there exist a number of challenges in the development and application of SASCs catering to HER. Firstly, in regard to preparation, the cost of preparing SASCs has to be lowered; the carbon-supported SASCs thus far are mostly obtained via pyrolysis, and more facile preparation strategies are still in need (for example, preparing the catalysts directly from bulk metals). Secondly, powerful in situ characterization techniques are still in urgent demand (such as TEM, environmental AC-HAADF-STEM, XAS, Mössbauer spectroscopy), as these techniques enable in situ monitoring of the reaction processes, identification of the real active sites, and help deepen our understanding of the structure-activity relationship at the atomic level.

Received 11 November 2019; accepted 28 December 2019;

published online 28 February 2020

1 Turner JA. Sustainable hydrogen production. Science, 2004, 305: 972-974

2 Zheng Y, Jiao Y, Qiao SZ. Engineering of carbon-based electrocatalysts for emerging energy conversion: From fundamentality 
to functionality. Adv Mater, 2015, 27: 5372-5378

3 Shi Y, Zhang B. Recent advances in transition metal phosphide nanomaterials: Synthesis and applications in hydrogen evolution reaction. Chem Soc Rev, 2016, 45: 1529-1541

4 Yi JD, Liu TT, Huang YB, et al. Solid-state synthesis of $\mathrm{MoS}_{2}$ nanorod from molybdenum-organic framework for efficient hydrogen evolution reaction. Sci China Mater, 2019, 62: 965-972

5 Cao Z, Chen Q, Zhang J, et al. Platinum-nickel alloy excavated nano-multipods with hexagonal close-packed structure and superior activity towards hydrogen evolution reaction. Nat Commun, 2017, 8: 15131-15137

6 Zou X, Zhang Y. Noble metal-free hydrogen evolution catalysts for water splitting. Chem Soc Rev, 2015, 44: 5148-5180

7 Zeng M, Li Y. Recent advances in heterogeneous electrocatalysts for the hydrogen evolution reaction. J Mater Chem A, 2015, 3: 14942-14962

8 Chen J, Lim B, Lee EP, et al. Shape-controlled synthesis of platinum nanocrystals for catalytic and electrocatalytic applications. Nano Today, 2009, 4: 81-95

9 Li Y, Zhang H, Xu T, et al. Under-water superaerophobic pineshaped Pt nanoarray electrode for ultrahigh-performance hydrogen evolution. Adv Funct Mater, 2015, 25: 1737-1744

10 Bai S, Wang C, Deng M, et al. Surface polarization matters: Enhancing the hydrogen-evolution reaction by shrinking Pt shells in Pt-Pd-graphene stack structures. Angew Chem Int Ed, 2014, 53: 12120-12124

11 Esposito DV, Chen JG. Monolayer platinum supported on tungsten carbides as low-cost electrocatalysts: Opportunities and limitations. Energy Environ Sci, 2011, 4: 3900-3912

12 Xing Z, Han C, Wang D, et al. Ultrafine Pt nanoparticle-decorated $\mathrm{Co}(\mathrm{OH})_{2}$ nanosheet arrays with enhanced catalytic activity toward hydrogen evolution. ACS Catal, 2017, 7: 7131-7135

13 Xie L, Ren $\mathrm{X}$, Liu Q, et al. A Ni(OH $)_{2}-\mathrm{PtO}_{2}$ hybrid nanosheet array with ultralow $\mathrm{Pt}$ loading toward efficient and durable alkaline hydrogen evolution. J Mater Chem A, 2018, 6: 1967-1970

14 Tiwari JN, Sultan S, Myung CW, et al. Multicomponent electrocatalyst with ultralow Pt loading and high hydrogen evolution activity. Nat Energy, 2018, 3: 773-782

15 Yang $\mathrm{H}$, Wang $\mathrm{C}, \mathrm{Hu} \mathrm{F}$, et al. Atomic-scale Pt clusters decorated on porous $\alpha-\mathrm{Ni}(\mathrm{OH})_{2}$ nanowires as highly efficient electrocatalyst for hydrogen evolution reaction. Sci China Mater, 2017, 60: 11211128

16 Wang S, Gao X, Hang X, et al. Ultrafine Pt nanoclusters confined in a calixarene-based $\left\{\mathrm{Ni}_{24}\right\}$ coordination cage for high-efficient hydrogen evolution reaction. J Am Chem Soc, 2016, 138: 1623616239

17 Chao T, Luo X, Chen W, et al. Atomically dispersed copperplatinum dual sites alloyed with palladium nanorings catalyze the hydrogen evolution reaction. Angew Chem Int Ed, 2017, 56: 16047-16051

18 Kerkeni S, Lamy-Pitara E, Barbier J. Copper-platinum catalysts prepared and characterized by electrochemical methods for the reduction of nitrate and nitrite. Catal Today, 2002, 75: 35-42

19 Zhong X, Wang L, Zhuang Z, et al. Double nanoporous structure with nanoporous PtFe embedded in graphene nanopores: Highly efficient bifunctional electrocatalysts for hydrogen evolution and oxygen reduction. Adv Mater Interfaces, 2017, 4: 1601029

20 Yang TT, Zhu H, Wan M, et al. Highly efficient and durable PtCo alloy nanoparticles encapsulated in carbon nanofibers for electrochemical hydrogen generation. Chem Commun, 2016, 52:
990-993

21 Zhang Z, Liu G, Cui X, et al. Crystal phase and architecture engineering of lotus-thalamus-shaped $\mathrm{Pt}-\mathrm{Ni}$ anisotropic superstructures for highly efficient electrochemical hydrogen evolution. Adv Mater, 2018, 30: 1801741

22 Oh A, Sa YJ, Hwang H, et al. Rational design of Pt-Ni-Co ternary alloy nanoframe crystals as highly efficient catalysts toward the alkaline hydrogen evolution reaction. Nanoscale, 2016, 8: 1637916386

23 Shen Y, Lua AC, Xi J, et al. Ternary platinum-copper-nickel nanoparticles anchored to hierarchical carbon supports as freestanding hydrogen evolution electrodes. ACS Appl Mater Interfaces, 2016, 8: 3464-3472

24 Gong M, Zhou W, Tsai MC, et al. Nanoscale nickel oxide/nickel heterostructures for active hydrogen evolution electrocatalysis. Nat Commun, 2014, 5: 4695

25 Deng J, Ren P, Deng D, et al. Highly active and durable nonprecious-metal catalysts encapsulated in carbon nanotubes for hydrogen evolution reaction. Energy Environ Sci, 2014, 7: 19191923

26 Deng J, Ren P, Deng D, et al. Enhanced electron penetration through an ultrathin graphene layer for highly efficient catalysis of the hydrogen evolution reaction. Angew Chem Int Ed, 2015, 54: $2100-2104$

27 Tavakkoli M, Kallio T, Reynaud O, et al. Single-shell carbonencapsulated iron nanoparticles: Synthesis and high electrocatalytic activity for hydrogen evolution reaction. Angew Chem Int Ed, 2015, 54: 4535-4538

28 Nørskov JK, Bligaard T, Logadottir A, et al. Trends in the exchange current for hydrogen evolution. J Electrochem Soc, 2005, 152: J23

29 Liu P, Rodriguez JA. Catalysts for hydrogen evolution from the [NiFe] hydrogenase to the $\mathrm{Ni}_{2} \mathrm{P}(001)$ surface: The importance of ensemble effect. J Am Chem Soc, 2005, 127: 14871-14878

30 Popczun EJ, McKone JR, Read CG, et al. Nanostructured nickel phosphide as an electrocatalyst for the hydrogen evolution reaction. J Am Chem Soc, 2013, 135: 9267-9270

$31 \mathrm{Xu} \mathrm{Y,} \mathrm{Wu} \mathrm{R,} \mathrm{Zhang} \mathrm{J,} \mathrm{et} \mathrm{al.} \mathrm{Anion-exchange} \mathrm{synthesis} \mathrm{of} \mathrm{nano-}$ porous FeP nanosheets as electrocatalysts for hydrogen evolution reaction. Chem Commun, 2013, 49: 6656-6658

32 Lu S, Zhuang Z. Electrocatalysts for hydrogen oxidation and evolution reactions. Sci China Mater, 2016, 59: 217-238

33 Zhao X, Luo D, Wang Y, et al. Reduced graphene oxide-supported CoP nanocrystals confined in porous nitrogen-doped carbon nanowire for highly enhanced lithium/sodium storage and hydrogen evolution reaction. Nano Res, 2019, 12: 2872-2880

34 Pan Y, Sun K, Liu S, et al. Core-shell ZIF-8@ZIF-67-derived CoP nanoparticle-embedded $\mathrm{N}$-doped carbon nanotube hollow polyhedron for efficient overall water splitting. J Am Chem Soc, 2018, 140: 2610-2618

35 Zhao D, Sun K, Cheong WC, et al. Synergistically interactive pyridinic-N-MoP sites: Identified active centers for enhanced hydrogen evolution in alkaline solution. Angew Chem, 2019, : ange. 201908760

36 Xiao P, Sk MA, Thia L, et al. Molybdenum phosphide as an efficient electrocatalyst for the hydrogen evolution reaction. Energy Environ Sci, 2014, 7: 2624-2629

37 Hao J, Yang W, Zhang Z, et al. Metal-organic frameworks derived $\mathrm{Co}_{x} \mathrm{Fe}_{1-x} \mathrm{P}$ nanocubes for electrochemical hydrogen evolution. Nanoscale, 2015, 7: 11055-11062 
38 Li Y, Zhang $\mathrm{H}$, Jiang $\mathrm{M}$, et al. Ternary NiCoP nanosheet arrays: An excellent bifunctional catalyst for alkaline overall water splitting. Nano Res, 2016, 9: 2251-2259

39 Tang $\mathrm{C}$, Gan L, Zhang R, et al. Ternary $\mathrm{Fe}_{x} \mathrm{Co}_{1-x} \mathrm{P}$ nanowire array as a robust hydrogen evolution reaction electrocatalyst with Ptlike activity: Experimental and theoretical insight. Nano Lett, 2016, 16: 6617-6621

40 Li Y, Zhang $\mathrm{H}$, Jiang $\mathrm{M}$, et al. 3D self-supported Fe-doped $\mathrm{Ni}_{2} \mathrm{P}$ nanosheet arrays as bifunctional catalysts for overall water splitting. Adv Funct Mater, 2017, 27: 1702513

41 Liang X, Zhang D, Wu Z, et al. The Fe-promoted MoP catalyst with high activity for water splitting. Appl Catal A-General, 2016, 524: $134-138$

42 Li J, Yan M, Zhou X, et al. Mechanistic insights on ternary $\mathrm{Ni}_{2-x} \mathrm{Co}_{x} \mathrm{P}$ for hydrogen evolution and their hybrids with graphene as highly efficient and robust catalysts for overall water splitting. Adv Funct Mater, 2016, 26: 6785-6796

43 Man HW, Tsang CS, Li MMJ, et al. Transition metal-doped nickel phosphide nanoparticles as electro- and photocatalysts for hydrogen generation reactions. Appl Catal B-Environ, 2019, 242: 186-193

44 Zhang LF, Ke X, Ou G, et al. Defective $\mathrm{MoS}_{2}$ electrocatalyst for highly efficient hydrogen evolution through a simple ball-milling method. Sci China Mater, 2017, 60: 849-856

45 Di Giovanni C, Wang WA, Nowak S, et al. Bioinspired iron sulfide nanoparticles for cheap and long-lived electrocatalytic molecular hydrogen evolution in neutral water. ACS Catal, 2014, 4: 681-687

46 Kong D, Cha JJ, Wang H, et al. First-row transition metal dichalcogenide catalysts for hydrogen evolution reaction. Energy Environ Sci, 2013, 6: 3553

47 Faber MS, Dziedzic R, Lukowski MA, et al. High-performance electrocatalysis using metallic cobalt pyrite $\left(\mathrm{CoS}_{2}\right)$ micro- and nanostructures. J Am Chem Soc, 2014, 136: 10053-10061

48 Peng S, Li L, Han X, et al. Cobalt sulfide nanosheet/graphene/ carbon nanotube nanocomposites as flexible electrodes for hydrogen evolution. Angew Chem, 2014, 126: 12802-12807

49 Tang $\mathrm{C}, \mathrm{Pu} \mathrm{Z}$, Liu $\mathrm{Q}$, et al. $\mathrm{NiS}_{2}$ nanosheets array grown on carbon cloth as an efficient 3D hydrogen evolution cathode. Electrochim Acta, 2015, 153: 508-514

50 Voiry D, Yamaguchi H, Li J, et al. Enhanced catalytic activity in strained chemically exfoliated $\mathrm{WS}_{2}$ nanosheets for hydrogen evolution. Nat Mater, 2013, 12: 850-855

51 Zhao X, Ma X, Sun J, et al. Enhanced catalytic activities of surfactant-assisted exfoliated $\mathrm{WS}_{2}$ nanodots for hydrogen evolution. ACS Nano, 2016, 10: 2159-2166

$52 \mathrm{Xu} \mathrm{S}, \mathrm{Li} \mathrm{D}, \mathrm{Wu}$ P. One-pot, facile, and versatile synthesis of monolayer $\mathrm{MoS}_{2} / \mathrm{WS}_{2}$ quantum dots as bioimaging probes and efficient electrocatalysts for hydrogen evolution reaction. Adv Funct Mater, 2015, 25: 1127-1136

53 Duan J, Chen S, Chambers BA, et al. 3D $\mathrm{WS}_{2}$ nanolayers@heteroatom-doped graphene films as hydrogen evolution catalyst electrodes. Adv Mater, 2015, 27: 4234-4241

54 Tributsch H, Bennett JC. Electrochemistry and photochemistry of $\mathrm{MoS}_{2}$ layer crystals. I. J Electroanal Chem Interfacial Electrochem, 1977, 81: 97-111

55 Hinnemann B, Moses PG, Bonde J, et al. Biomimetic hydrogen evolution: $\mathrm{MoS}_{2}$ nanoparticles as catalyst for hydrogen evolution. J Am Chem Soc, 2005, 127: 5308-5309

56 Jaramillo TF, Jørgensen KP, Bonde J, et al. Identification of active edge sites for electrochemical $\mathrm{H}_{2}$ evolution from $\mathrm{MoS}_{2}$ nanocatalysts. Science, 2007, 317: 100-102

57 Liu D, Xu W, Liu Q, et al. Unsaturated-sulfur-rich $\mathrm{MoS}_{2}$ nanosheets decorated on free-standing SWNT film: Synthesis, characterization and electrocatalytic application. Nano Res, 2016, 9: 2079-2087

58 Kong D, Wang H, Cha JJ, et al. Synthesis of $\mathrm{MoS}_{2}$ and $\mathrm{MoSe}_{2}$ films with vertically aligned layers. Nano Lett, 2013, 13: 13411347

59 Kibsgaard J, Chen Z, Reinecke BN, et al. Engineering the surface structure of $\mathrm{MoS}_{2}$ to preferentially expose active edge sites for electrocatalysis. Nat Mater, 2012, 11: 963-969

60 Wang Z, Li Q, Xu H, et al. Controllable etching of $\mathrm{MoS}_{2}$ basal planes for enhanced hydrogen evolution through the formation of active edge sites. Nano Energy, 2018, 49: 634-643

$61 \mathrm{Li} \mathrm{H}$, Tsai C, Koh AL, et al. Activating and optimizing $\mathrm{MoS}_{2}$ basal planes for hydrogen evolution through the formation of strained sulphur vacancies. Nat Mater, 2016, 15: 48-53

62 Li H, Du M, Mleczko MJ, et al. Kinetic study of hydrogen evolution reaction over strained $\mathrm{MoS}_{2}$ with sulfur vacancies using scanning electrochemical microscopy. J Am Chem Soc, 2016, 138: 5123-5129

63 Tsai C, Li H, Park S, et al. Electrochemical generation of sulfur vacancies in the basal plane of $\mathrm{MoS}_{2}$ for hydrogen evolution. Nat Commun, 2017, 8: 15113

64 Li G, Zhang D, Qiao Q, et al. All the catalytic active sites of $\mathrm{MoS}_{2}$ for hydrogen evolution. J Am Chem Soc, 2016, 138: 16632-16638

65 Zhu J, Wang ZC, Dai H, et al. Boundary activated hydrogen evolution reaction on monolayer $\mathrm{MoS}_{2}$. Nat Commun, 2019, 10: 1348

66 Gao MR, Lin ZY, Zhuang TT, et al. Mixed-solution synthesis of sea urchin-like NiSe nanofiber assemblies as economical Pt-free catalysts for electrochemical $\mathrm{H}_{2}$ production. J Mater Chem, 2012, 22: 13662

67 Zhou H, Yu F, Liu Y, et al. Outstanding hydrogen evolution reaction catalyzed by porous nickel diselenide electrocatalysts. Energy Environ Sci, 2017, 10: 1487-1492

68 Kong D, Wang $\mathrm{H}, \mathrm{Lu} \mathrm{Z}$, et al. $\mathrm{CoSe}_{2}$ nanoparticles grown on carbon fiber paper: An efficient and stable electrocatalyst for hydrogen evolution reaction. J Am Chem Soc, 2014, 136: 48974900

69 Tsai C, Chan K, Abild-Pedersen F, et al. Active edge sites in $\mathrm{MoSe}_{2}$ and $\mathrm{WSe}_{2}$ catalysts for the hydrogen evolution reaction: A density functional study. Phys Chem Chem Phys, 2014, 16: 13156-13164

70 Liu Z, Li N, Zhao H, et al. Colloidally synthesized $\mathrm{MoSe}_{2} /$ graphene hybrid nanostructures as efficient electrocatalysts for hydrogen evolution. J Mater Chem A, 2015, 3: 19706-19710

71 Tang H, Dou K, Kaun CC, et al. $\mathrm{MoSe}_{2}$ nanosheets and their graphene hybrids: Synthesis, characterization and hydrogen evolution reaction studies. J Mater Chem A, 2014, 2: 360-364

72 Yin Y, Zhang Y, Gao T, et al. Synergistic phase and disorder engineering in $1 \mathrm{~T}-\mathrm{MoSe}_{2}$ nanosheets for enhanced hydrogenevolution reaction. Adv Mater, 2017, 29: 1700311

73 Peng X, Hu L, Wang L, et al. Vanadium carbide nanoparticles encapsulated in graphitic carbon network nanosheets: A highefficiency electrocatalyst for hydrogen evolution reaction. Nano Energy, 2016, 26: 603-609

74 Xiong W, Guo Q, Guo Z, et al. Atomic layer deposition of nickel carbide for supercapacitors and electrocatalytic hydrogen evolu- 
tion. J Mater Chem A, 2018, 6: 4297-4304

75 Meyer S, Nikiforov AV, Petrushina IM, et al. Transition metal carbides ( $\mathrm{WC}, \mathrm{Mo}_{2} \mathrm{C}, \mathrm{TaC}, \mathrm{NbC}$ ) as potential electrocatalysts for the hydrogen evolution reaction (HER) at medium temperatures. Int J Hydrogen Energy, 2015, 40: 2905-2911

76 Levy RB, Boudart M. Platinum-like behavior of tungsten carbide in surface catalysis. Science, 1973, 181: 547-549

77 Bennett LH, Cuthill JR, McAlister AJ, et al. Electronic structure and catalytic behavior of tungsten carbide. Science, 1974, 184: 563-565

$78 \mathrm{Xu} \mathrm{YT,} \mathrm{Xiao} \mathrm{X,} \mathrm{Ye} \mathrm{ZM,} \mathrm{et} \mathrm{al.} \mathrm{Cage-confinement} \mathrm{pyrolysis} \mathrm{route} \mathrm{to}$ ultrasmall tungsten carbide nanoparticles for efficient electrocatalytic hydrogen evolution. J Am Chem Soc, 2017, 139: 52855288

79 Kim SK, Qiu Y, Zhang YJ, et al. Nanocomposites of transitionmetal carbides on reduced graphite oxide as catalysts for the hydrogen evolution reaction. Appl Catal B-Environ, 2018, 235 : 36-44

80 Ma R, Zhou Y, Chen Y, et al. Ultrafine molybdenum carbide nanoparticles composited with carbon as a highly active hydrogen-evolution electrocatalyst. Angew Chem Int Ed, 2015, 54: 14723-14727

81 Ko YJ, Cho JM, Kim I, et al. Tungsten carbide nanowalls as electrocatalyst for hydrogen evolution reaction: New approach to durability issue. Appl Catal B-Environ, 2017, 203: 684-691

$82 \mathrm{Wu} \mathrm{HB}, \mathrm{Xia} \mathrm{BY}, \mathrm{Yu} \mathrm{L}$, et al. Porous molybdenum carbide nanooctahedrons synthesized via confined carburization in metalorganic frameworks for efficient hydrogen production. Nat Commun, 2015, 6: 6512

83 Humagain G, MacDougal K, MacInnis J, et al. Highly efficient, biochar-derived molybdenum carbide hydrogen evolution electrocatalyst. Adv Energy Mater, 2018, 8: 1801461

84 Ren B, Li D, Jin Q, et al. A self-supported porous WN nanowire array: An efficient 3D electrocatalyst for the hydrogen evolution reaction. J Mater Chem A, 2017, 5: 19072-19078

85 Xing Z, Li Q, Wang D, et al. Self-supported nickel nitride as an efficient high-performance three-dimensional cathode for the alkaline hydrogen evolution reaction. Electrochim Acta, 2016, 191: 841-845

86 You B, Liu X, Hu G, et al. Universal surface engineering of transition metals for superior electrocatalytic hydrogen evolution in neutral water. J Am Chem Soc, 2017, 139: 12283-12290

87 Xie J, Li S, Zhang X, et al. Atomically-thin molybdenum nitride nanosheets with exposed active surface sites for efficient hydrogen evolution. Chem Sci, 2014, 5: 4615-4620

88 Liang HW, Brüller S, Dong R, et al. Molecular metal- $\mathrm{N}_{x}$ centres in porous carbon for electrocatalytic hydrogen evolution. Nat Commun, 2015, 6: 7992

89 Yu F, Zhou H, Zhu Z, et al. Three-dimensional nanoporous iron nitride film as an efficient electrocatalyst for water oxidation. ACS Catal, 2017, 7: 2052-2057

$90 \mathrm{Yu}$ L, Song S, McElhenny B, et al. A universal synthesis strategy to make metal nitride electrocatalysts for hydrogen evolution reaction. J Mater Chem A, 2019, 7: 19728-19732

91 Han Y, Yue X, Jin Y, et al. Hydrogen evolution reaction in acidic media on single-crystalline titanium nitride nanowires as an efficient non-noble metal electrocatalyst. J Mater Chem A, 2016, 4: 3673-3677

92 Zhu Y, Chen G, Zhong Y, et al. Rationally designed hierarchically structured tungsten nitride and nitrogen-rich graphene-like car- bon nanocomposite as efficient hydrogen evolution electrocatalyst. Adv Sci, 2018, 5: 1700603

93 Los P, Lasia A. Electrocatalytic properties of amorphous nickel boride electrodes for hydrogen evolution reaction in alkaline solution. J Electroanal Chem, 1992, 333: 115-125

94 Albert B, Hillebrecht H. Boron: Elementary challenge for experimenters and theoreticians. Angew Chem Int Ed, 2009, 48: 8640-8668

95 Masa J, Weide P, Peeters D, et al. Amorphous cobalt boride $\left(\mathrm{Co}_{2} \mathrm{~B}\right)$ as a highly efficient nonprecious catalyst for electrochemical water splitting: Oxygen and hydrogen evolution. Adv Energy Mater, 2016, 6: 1502313

96 Lu W, Liu T, Xie L, et al. In situ derived Co-B nanoarray: A highefficiency and durable 3D bifunctional electrocatalyst for overall alkaline water splitting. Small, 2017, 13: 1700805

97 Zhang P, Wang M, Yang Y, et al. Electroless plated Ni-B films as highly active electrocatalysts for hydrogen production from water over a wide pH range. Nano Energy, 2016, 19: 98-107

98 Vrubel H, Hu X. Molybdenum boride and carbide catalyze hydrogen evolution in both acidic and basic solutions. Angew Chem Int Ed, 2012, 51: 12703-12706

99 Park H, Encinas A, Scheifers JP, et al. Boron-dependency of molybdenum boride electrocatalysts for the hydrogen evolution reaction. Angew Chem Int Ed, 2017, 56: 5575-5578

100 Gupta S, Patel N, Fernandes R, et al. Co-Ni-B nanocatalyst for efficient hydrogen evolution reaction in wide $\mathrm{pH}$ range. Appl Catal B-Environ, 2016, 192: 126-133

$101 \mathrm{Xu} \mathrm{N}$, Cao G, Chen Z, et al. Cobalt nickel boride as an active electrocatalyst for water splitting. J Mater Chem A, 2017, 5: 12379-12384

102 Cao S, Tao FF, Tang Y, et al. Size- and shape-dependent catalytic performances of oxidation and reduction reactions on nanocatalysts. Chem Soc Rev, 2016, 45: 4747-4765

103 Pan Y, Liu Y, Zhao J, et al. Monodispersed nickel phosphide nanocrystals with different phases: Synthesis, characterization and electrocatalytic properties for hydrogen evolution. J Mater Chem A, 2015, 3: 1656-1665

104 Pan Y, Lin Y, Chen Y, et al. Cobalt phosphide-based electrocatalysts: Synthesis and phase catalytic activity comparison for hydrogen evolution. J Mater Chem A, 2016, 4: 4745-4754

105 Callejas JF, Read CG, Popczun EJ, et al. Nanostructured $\mathrm{Co}_{2} \mathrm{P}$ electrocatalyst for the hydrogen evolution reaction and direct comparison with morphologically equivalent CoP. Chem Mater, 2015, 27: 3769-3774

106 Yin Y, Han J, Zhang Y, et al. Contributions of phase, sulfur vacancies, and edges to the hydrogen evolution reaction catalytic activity of porous molybdenum disulfide nanosheets. J Am Chem Soc, 2016, 138: 7965-7972

107 Lukowski MA, Daniel AS, Meng F, et al. Enhanced hydrogen evolution catalysis from chemically exfoliated metallic $\mathrm{MoS}_{2}$ nanosheets. J Am Chem Soc, 2013, 135: 10274-10277

108 Sun K, Liu Y, Pan Y, et al. Targeted bottom-up synthesis of 1Tphase $\mathrm{MoS}_{2}$ arrays with high electrocatalytic hydrogen evolution activity by simultaneous structure and morphology engineering. Nano Res, 2018, 11: 4368-4379

109 Yu X, Yu ZY, Zhang XL, et al. "Superaerophobic" nickel phosphide nanoarray catalyst for efficient hydrogen evolution at ultrahigh current densities. J Am Chem Soc, 2019, 141: 7537-7543

110 Wang J, Yang Q, Wang M, et al. Rose petals with a novel and steady air bubble pinning effect in aqueous media. Soft Matter, 
2012, 8: 2261-2266

$111 \mathrm{Lu}$ Z, Zhu W, Yu X, et al. Ultrahigh hydrogen evolution performance of under-water "Superaerophobic" $\mathrm{MoS}_{2}$ nanostructured electrodes. Adv Mater, 2014, 26: 2683-2687

112 Zhang J, Sui R, Xue Y, et al. Direct synthesis of parallel doped N$\mathrm{MoP} / \mathrm{N}-\mathrm{CNT}$ as highly active hydrogen evolution reaction catalyst. Sci China Mater, 2019, 62: 690-698

113 Qu G, Wu T, Yu Y, et al. Rational design of phosphorus-doped cobalt sulfides electrocatalysts for hydrogen evolution. Nano Res, 2019, 12: 2960-2965

114 Wang DY, Gong M, Chou HL, et al. Highly active and stable hybrid catalyst of cobalt-doped $\mathrm{FeS}_{2}$ nanosheets-carbon nanotubes for hydrogen evolution reaction. J Am Chem Soc, 2015, 137: 1587-1592

115 Hou Y, Qiu M, Zhang T, et al. Ternary porous cobalt phosphoselenide nanosheets: An efficient electrocatalyst for electrocatalytic and photoelectrochemical water splitting. Adv Mater, 2017, 29: 1701589

116 Kibsgaard J, Jaramillo TF. Molybdenum phosphosulfide: An active, acid-stable, earth-abundant catalyst for the hydrogen evolution reaction. Angew Chem Int Ed, 2014, 53: 14433-14437

117 Cabán-Acevedo M, Stone ML, Schmidt JR, et al. Efficient hydrogen evolution catalysis using ternary pyrite-type cobalt phosphosulphide. Nat Mater, 2015, 14: 1245-1251

118 Hong W, Jian C, Wang G, et al. Self-supported nanoporous cobalt phosphosulfate electrodes for efficient hydrogen evolution reaction. Appl Catal B-Environ, 2019, 251: 213-219

119 Chen Z, Song Y, Cai J, et al. Tailoring the d-band centers enables $\mathrm{Co}_{4} \mathrm{~N}$ nanosheets to be highly active for hydrogen evolution catalysis. Angew Chem Int Ed, 2018, 57: 5076-5080

120 Pan Y, Sun K, Lin Y, et al. Electronic structure and d-band center control engineering over $\mathrm{M}$-doped $\mathrm{CoP}(\mathrm{M}=\mathrm{Ni}, \mathrm{Mn}, \mathrm{Fe})$ hollow polyhedron frames for boosting hydrogen production. Nano Energy, 2019, 56: 411-419

121 Tan C, Chen J, Wu XJ, et al. Epitaxial growth of hybrid nanostructures. Nat Rev Mater, 2018, 3: 17089

122 Zhao G, Rui K, Dou SX, et al. Heterostructures for electrochemical hydrogen evolution reaction: A review. Adv Funct Mater, 2018, 28: 1803291

123 Lin Y, Sun K, Liu S, et al. Construction of CoP/NiCoP nanotadpoles heterojunction interface for wide $\mathrm{pH}$ hydrogen evolution electrocatalysis and supercapacitor. Adv Energy Mater, 2019, 9: 1901213

124 Lin Y, Pan Y, Liu S, et al. Construction of multi-dimensional core/shell Ni/NiCoP nano-heterojunction for efficient electrocatalytic water splitting. Appl Catal B-Environ, 2019, 259: 118039

125 Wang $\mathrm{P}$, Zhang X, Zhang J, et al. Precise tuning in platinumnickel/nickel sulfide interface nanowires for synergistic hydrogen evolution catalysis. Nat Commun, 2017, 8: 14580

126 Liu D, Li X, Chen S, et al. Atomically dispersed platinum supported on curved carbon supports for efficient electrocatalytic hydrogen evolution. Nat Energy, 2019, 4: 512-518

127 Zhang J, Zhao Y, Guo X, et al. Single platinum atoms immobilized on an MXene as an efficient catalyst for the hydrogen evolution reaction. Nat Catal, 2018, 1: 985-992

128 Ye S, Luo F, Zhang Q, et al. Highly stable single Pt atomic sites anchored on aniline-stacked graphene for hydrogen evolution reaction. Energy Environ Sci, 2019, 12: 1000-1007

129 Zhang $\mathrm{H}$, An $\mathrm{P}$, Zhou W, et al. Dynamic traction of latticeconfined platinum atoms into mesoporous carbon matrix for hydrogen evolution reaction. Sci Adv, 2018, 4: eaao6657

130 Zhang L, Han L, Liu H, et al. Potential-cycling synthesis of single platinum atoms for efficient hydrogen evolution in neutral media. Angew Chem Int Ed, 2017, 56: 13694-13698

131 Jiang K, Liu B, Luo M, et al. Single platinum atoms embedded in nanoporous cobalt selenide as electrocatalyst for accelerating hydrogen evolution reaction. Nat Commun, 2019, 10: 1743

132 Yang J, Chen B, Liu X, et al. Efficient and robust hydrogen evolution: Phosphorus nitride imide nanotubes as supports for anchoring single ruthenium sites. Angew Chem Int Ed, 2018, 57: 9495-9500

133 Ramalingam V, Varadhan P, Fu HC, et al. Heteroatom-mediated interactions between ruthenium single atoms and an MXene support for efficient hydrogen evolution. Adv Mater, 2019, 31: 1903841

134 Zhang L, Si R, Liu H, et al. Atomic layer deposited Pt-Ru dualmetal dimers and identifying their active sites for hydrogen evolution reaction. Nat Commun, 2019, 10: 4936

135 Lai W, Zhang L, Hua W, et al. General $\pi$-electron-assisted strategy for $\mathrm{Ir}, \mathrm{Pt}, \mathrm{Ru}, \mathrm{Pd}, \mathrm{Fe}, \mathrm{Ni}$ single-atom electrocatalysts with bifunctional active sites for highly efficient water splitting. Angew Chem, 2019, 131: 11994-11999

136 Zhang L, Jia Y, Gao G, et al. Graphene defects trap atomic Ni species for hydrogen and oxygen evolution reactions. Chem, 2018, 4: 285-297

137 Li M, Duanmu K, Wan C, et al. Single-atom tailoring of platinum nanocatalysts for high-performance multifunctional electrocatalysis. Nat Catal, 2019, 2: 495-503

138 Zhang H, Yu L, Chen T, et al. Surface modulation of hierarchical $\mathrm{MoS}_{2}$ nanosheets by Ni single atoms for enhanced electrocatalytic hydrogen evolution. Adv Funct Mater, 2018, 28: 1807086

139 Ling C, Shi L, Ouyang Y, et al. Nanosheet supported single-metal atom bifunctional catalyst for overall water splitting. Nano Lett, 2017, 17: 5133-5139

140 Xue Y, Huang B, Yi Y, et al. Anchoring zero valence single atoms of nickel and iron on graphdiyne for hydrogen evolution. Nat Commun, 2018, 9: 1460

141 Pan Y, Liu S, Sun K, et al. A bimetallic Zn/Fe polyphthalocyaninederived single-atom $\mathrm{Fe}-\mathrm{N}_{4}$ catalytic site: A superior trifunctional catalyst for overall water splitting and Zn-air batteries. Angew Chem Int Ed, 2018, 57: 8614-8618

142 Fei H, Dong J, Arellano-Jiménez MJ, et al. Atomic cobalt on nitrogen-doped graphene for hydrogen generation. Nat Commun, 2015, 6: 8668

143 Fei H, Dong J, Wan C, et al. Microwave-assisted rapid synthesis of graphene-supported single atomic metals. Adv Mater, 2018, 30: 1802146

144 Sun T, Zhao S, Chen W, et al. Single-atomic cobalt sites embedded in hierarchically ordered porous nitrogen-doped carbon as a superior bifunctional electrocatalyst. Proc Natl Acad Sci USA, 2018, 115: 12692-12697

145 Chen W, Pei J, He CT, et al. Rational design of single molybdenum atoms anchored on $\mathrm{N}$-doped carbon for effective hydrogen evolution reaction. Angew Chem Int Ed, 2017, 56: 16086-16090

146 Chen W, Pei J, He CT, et al. Single tungsten atoms supported on MOF-derived N-doped carbon for robust electrochemical hydrogen evolution. Adv Mater, 2018, 30: 1800396

147 Zhao Y, Ling T, Chen S, et al. Non-metal single-iodine-atom electrocatalysts for the hydrogen evolution reaction. Angew Chem Int Ed, 2019, 58: 12252-12257 
148

Cheng N, Stambula S, Wang D, et al. Platinum single-atom and cluster catalysis of the hydrogen evolution reaction. Nat Commun, 2016, 7: 13638-13643

149 Yin XP, Wang HJ, Tang SF, et al. Engineering the coordination environment of single-atom platinum anchored on graphdiyne for optimizing electrocatalytic hydrogen evolution. Angew Chem Int Ed, 2018, 57: 9382-9386

Acknowledgements This work was supported by the National Key R\&D Program of China (2016YFA0202801, 2017YFA0700101 and 2018YFA0702003), the National Natural Science Foundation of China (21925202, 21872076 and 21890383), Beijing Natural Science Foundation (JQ18007), the Fundamental Research Funds for the Central Universities (19CX02008A), the Petro China Innovation Foundation (2019D-5007-0401), Taishan Scholars Program of Shandong Province (tsqn201909065), and Tsinghua University Initiative Scientific Research Program.

Author contributions Pan $\mathrm{Y}$ and Chen $\mathrm{C}$ wrote the manuscript. Zhang $\mathrm{C}$ and Lin $\mathrm{Y}$ revised the manuscript. Liu $\mathrm{Z}$ and Wang $\mathrm{M}$ drew the figures. Chen $\mathrm{C}$ supervised the project, directed the research and established the final version of the manuscript. All authors participated in the general discussion.

Conflict of interest interests.

The authors declare no competing financial

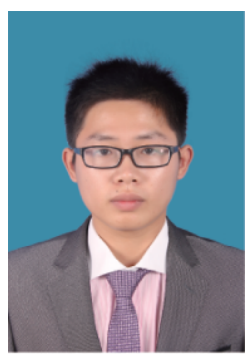

Yuan Pan received his $\mathrm{PhD}$ from the College of Chemical Engineering, China University of Petroleum (East China) in 2016. After postdoctoral work at Tsinghua University, he joined the College of Chemical Engineering at China University of Petroleum (East China) as an associate professor in 2019. His research interests focus on the design and synthesis of novel nanomaterials and single-atom materials for catalytic application.

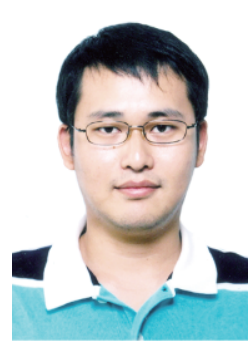

Chen Chen received his BS degree from the Department of Chemistry, Beijing Institute of Technology in 2006, and his $\mathrm{PhD}$ degree from the Department of Chemistry, Tsinghua University in 2011. After postdoctoral work at Lawrence Berkeley National Laboratory, he joined the Department of Chemistry at Tsinghua University as an associate professor in 2015. His research interests focus on nanomaterials and catalysis.

\section{析氢反应中电催化剂设计与构效关系：从纳米结 构到单原子}

潘原 ${ }^{1,2}$, 张超 ${ }^{2}$, 林燕 ${ }^{3}$, 刘智 ${ }^{1}$, 王敏敏 ${ }^{1}$, 陈晨 ${ }^{2 *}$

摘要 随着全球能源需求的增加和环境污染的加剧, 氢能作为一种 新型的能源越来越受到广泛的关注. 高效催化剂的设计和开发是 制氢研究中极具挑战性的难题. 催化剂的表界面组成与结构对其 性能具有极其重要的影响, 如何科学地设计调控催化材料表界面 结构来提高电催化析氢反应的活性和稳定性一直是催化领域研究 的重点. 本综述针对电催化析氢体系中的多尺度催化剂设计合成 为研究对象, 以纳米结构催化剂的设计及构效关系为出发点, 总结 了目前针对电催化析氢反应的纳米催化剂的合成及构效关系的研 究进展, 从原子尺度提出纳米催化剂高活性的起源. 结合目前报道 的各种单原子催化剂的设计合成、在析氢反应中的应用及构效关 系的研究, 讨论了设计定向单原子位点析氢催化剂的方向, 同时对 电解水制氢催化剂的发展趋势和挑战进行了展望. 